\title{
Status of the Tibetan Plateau observatory (Tibet-Obs) and a 10-year (2009-2019) surface soil moisture dataset
}

\author{
Pei Zhang ${ }^{1,2}$, Donghai Zheng ${ }^{2}$, Rogier van der Velde ${ }^{1}$, Jun Wen ${ }^{3}$, Yijian Zeng ${ }^{1}$, Xin Wang ${ }^{4}$, \\ Zuoliang Wang ${ }^{4}$, Jiali Chen ${ }^{2,5}$, and Zhongbo $\mathrm{Su}^{1}$ \\ ${ }^{1}$ Faculty of Geo-Information Science and Earth Observation (ITC), University of Twente, \\ Enschede, 7514AE, the Netherlands \\ ${ }^{2}$ National Tibetan Plateau Data Center, Key Laboratory of Tibetan Environmental Changes and Land Surface \\ Processes, Institute of Tibetan Plateau Research, Chinese Academy of Sciences, Beijing, 100101, China \\ ${ }^{3}$ College of Atmospheric Sciences, Chengdu University of Information Technology, Chengdu, 610225, China \\ ${ }^{4}$ Northwest Institute of Eco-Environment and Resources, Chinese Academy of Sciences, \\ Lanzhou, 730000, China \\ ${ }^{5}$ College of Earth and Environmental Sciences, Lanzhou University, Lanzhou, 730000, China \\ Correspondence: Donghai Zheng (zhengd@itpcas.ac.cn) and Zhongbo Su (z.su@utwente.nl)
}

Received: 27 July 2020 - Discussion started: 16 October 2020

Revised: 16 May 2021 - Accepted: 18 May 2021 - Published: 1 July 2021

\begin{abstract}
The Tibetan Plateau observatory (Tibet-Obs) of plateau scale soil moisture and soil temperature was established 10 years ago and has been widely used to calibrate/validate satellite- and model-based soil moisture (SM) products for their applications to the Tibetan Plateau (TP). This paper reports on the status of the Tibet-Obs and presents a 10-year (2009-2019) surface SM dataset produced based on in situ measurements taken at a depth of $5 \mathrm{~cm}$ collected from the Tibet-Obs that consists of three regional-scale SM monitoring networks, i.e. the Maqu, Naqu, and Ngari (including Ali and Shiquanhe) networks. This surface SM dataset includes the original 15 min in situ measurements collected by multiple SM monitoring sites of the three networks and the spatially upscaled SM records produced for the Maqu and Shiquanhe networks. Comparisons between four spatial upscaling methods - i.e. arithmetic averaging, Voronoi diagrams, time stability, and apparent thermal inertia - show that the arithmetic average of the monitoring sites with long-term (i.e. $\geq 6$-year) continuous measurements is found to be most suitable to produce the upscaled SM records. Trend analysis of the 10-year upscaled SM records indicates that the Shiquanhe network in the western part of the TP is getting wet, while there is no significant trend found for the Maqu network in the east. To further demonstrate the uniqueness of the upscaled SM records in validating existing SM products for a long-term period ( $\sim 10$ years), the reliability of three reanalysis datasets is evaluated for the Maqu and Shiquanhe networks. It is found that current model-based SM products still show deficiencies in representing the measured SM dynamics in the Tibetan grassland (i.e. Maqu) and desert ecosystems (i.e. Shiquanhe). The dataset would also be valuable for calibrating/validating long-term satellite-based SM products, evaluation of SM upscaling methods, development of data fusion methods, and quantifying the coupling of SM and precipitation at a 10-year scale. The dataset is available in the 4TU.ResearchData repository at https://doi.org/10.4121/12763700.v7 (Zhang et al., 2020).
\end{abstract}




\section{Introduction}

The Tibetan Plateau observatory (Tibet-Obs) of plateau scale soil moisture and soil temperature (SMST) was set up in 2006 and became fully operational in 2010 with the objective of calibration/validation of satellite- and model-based soil moisture (SM) products at a regional scale (Su et al., 2011). The Tibet-Obs mainly consists of three regional-scale SMST monitoring networks - i.e. Maqu, Naqu, and Ngari - which cover different climate and land surface conditions across the Tibetan Plateau (TP), and each includes multiple in situ SMST monitoring sites. The SM data collected from the Tibet-Obs have been widely used in the past decade to calibrate/validate satellite- and model-based SM products (e.g. Su et al., 2013; Zheng et al., 2015a, b; Colliander et al., 2017), to evaluate and develop SM upscaling methods (e.g. Qin et al., 2013, 2015), to assess algorithms for the retrieval of SM for microwave remote sensing observations (e.g. van der Velde et al., 2014a, b; Zheng et al., 2018a, b, 2019), and to assess fusion methods for merging in situ SM and satelliteor model-based products (e.g. Yang et al., 2020; Zeng et al., 2016).

Key information and outcomes of the main scientific applications using the Tibet-Obs SM data are summarized in Table 1. As shown in Table 1, the state-of-the-art satellite- and model-based products are useful but still show various types of deficiencies specific to the hydro-meteorological conditions on the TP, and further evaluation and improvement of these products remain imperative. In general, previous studies mainly focused on the evaluation of SM products using the Tibet-Obs data for short-term periods (i.e. less than 5 years), while up to now the Tibet-Obs has collected in situ measurements for more than 10 years. Development of a close-to-10-year Tibet-Obs in situ SM dataset will further enhance the calibration/validation of long-term satellite- and model-based products and is valuable for better understanding the hydro-meteorological response to climate change. However, SM is highly variable in both space and time, and data gaps in the availability of measurements taken from individual monitoring sites hinder scientific studies covering longer time periods, e.g. more than 5 years. Therefore, it is still challenging to obtain accurate long-term regional-scale SM due to the sparse nature of monitoring networks and highly variable soil conditions.

Spatial upscaling is usually necessary to obtain the regional-scale SM of an in situ network from multiple monitoring sites to match the footprint of satellite- or the grid cell of model-based products. A frequently used approach for upscaling point-scale SM measurements to a spatial domain is the arithmetic average, mostly because of its simplicity ( $\mathrm{Su}$ et al., 2011, 2013). Many other studies also adopted weighted averaging methods, whereby the weights are assigned to account for spatial heterogeneity in the area covered by in situ monitoring sites within the network. For instance, Colliander et al. (2017) employed Voronoi diagrams to determine the weights of individual monitoring sites within core regionalscale networks used for the worldwide validation of the Soil Moisture Active Passive (SMAP) SM products. Dente et al. (2012b) established weights based on the topography and soil texture for the sites of the Tibet-Obs's Maqu network. Qin et al. $(2013,2015)$ derived the weights by minimizing a cost function between in situ SM of individual monitoring sites and a representative SM of the network that is estimated using the apparent thermal inertia (ATI)-based method (Gao et al., 2017). Alternative methods, such as time stability and ridge regression, have been adopted in other investigations (i.e. Zhao et al., 2013; Kang et al., 2017). While a large number of studies have assessed the performance of different upscaling methods in other areas such as the Tonzi Ranch network in California and the Heihe watershed (Moghaddam et al., 2014; Wang et al., 2014), only a few investigations have been done for the TP (Gao et al., 2017; Qin et al., 2015). Since the number of monitoring sites changes over time due to damage to SM sensors in the Tibet-Obs, it is essential to evaluate and select an appropriate upscaling method for a limited number of monitoring sites (i.e. $\leq$ four sites).

This paper reports on the status of the Tibet-Obs and presents a long-term in situ SM and spatially upscaled SM dataset for the period between 2009 and 2019. The 10-year SM dataset of Tibet-Obs includes the original $15 \mathrm{~min}$ in situ measurements taken at a depth of $5 \mathrm{~cm}$ collected from the three regional-scale networks (i.e. Maqu, Naqu, and Ngari as shown in Fig. 1) and the continuous regional-scale SM produced using an appropriately selected spatial upscaling method. To achieve this, four methods are studied, namely the arithmetic average (AA), Voronoi diagram (VD), time stability (TS), and apparent thermal inertia (ATI) methods. The seasonal dynamic and trend of the regional-scale SM time series are analysed, and the 10-year SM dataset is used to validate three model-based SM products, i.e. ERA5-Land (Muñoz-Sabater et al., 2018), MERRA2 (Modern-Era Retrospective Analysis for Research and Applications version 2) (GMAO, 2015), and GLDAS Noah (Global Land Data Assimilation System with Noah Land Surface Model) (Rodell et al., 2004).

This paper is organized as follows. Section 2 describes the status of the Tibet-Obs and the in situ SM measurements, as well as the precipitation data and the three model-based SM products. Section 3 introduces the four SM spatial upscaling methods, the Mann-Kendall trend test and Sen's slope estimate, and performance metrics. Section 4 presents the inter-comparison of the four SM spatial upscaling methods, the production and analysis of the regional-scale SM dataset for a 10-year period, and its application to validate the three model-based SM products. Section 5 provides the discussion and suggestions for maintaining Tibet-Obs. Section 6 documents the information on data availability, and the conclusions are drawn in Sect. 7. 
Table 1. Summary of the main Tibet-Obs applications and corresponding findings.

\begin{tabular}{|c|c|c|}
\hline Literature & In situ data & Satellite- and/or model-based products \\
\hline $\begin{array}{l}\text { Dente et al. } \\
\text { (2012a) }\end{array}$ & $\begin{array}{l}\text { Maqu network, period } \\
\text { of } 2010\end{array}$ & $\begin{array}{l}\text { Soil Moisture and Ocean Salinity (SMOS) } \\
\text { Level } 2 \text { SM product }\end{array}$ \\
\hline $\begin{array}{l}\text { Dente et al. } \\
(2012 b)\end{array}$ & $\begin{array}{l}\text { Maqu network, period } \\
\text { between } 2008 \text { and } 2009\end{array}$ & $\begin{array}{l}\text { Land parameter retrieval model (LPRM) } \\
\text { with the Advanced Microwave Scanning } \\
\text { Radiometer for the Earth Observation Sys- } \\
\text { tem (AMSR-E) SM product, Advanced } \\
\text { Scatterometer (ASCAT) SM product }\end{array}$ \\
\hline $\begin{array}{l}\text { Zeng et al. } \\
(2015)\end{array}$ & $\begin{array}{l}\text { Maqu network, period } \\
\text { between } 2008 \text { and } 2010\end{array}$ & $\begin{array}{l}\text { SMOS Level } 3 \text { SM product (version 2.45), } \\
\text { AMSR-E SM product (NASA version 6), } \\
\text { LPRM (version 2) and Japan Aerospace } \\
\text { Exploration Agency (JAXA version 700), } \\
\text { AMSR2 Level } 3 \text { SM products (version } \\
\text { 1.11), ASCAT SM product (version TU- } \\
\text { Wien-WARP 5.5), ERA-Interim SM prod- } \\
\text { uct (version 2.0), and Essential Climate } \\
\text { Variable SM product (ECV version } 02.0 \text { ) }\end{array}$ \\
\hline
\end{tabular}

Key findings

The SMOS product exhibits a systematic dry bias $\left(0.13 \mathrm{~m}^{3} \mathrm{~m}^{-3}\right)$ in the Maqu network.

(i) The weighted average of SM depends on the percentage spatial coverage strata can be regarded as the ground reference.

(ii) The AMSR-E and ASCAT products are able to provide reasonable area SM during monsoon seasons.

(i) The ECV and ERA products give the best performance, and all products are able to capture the SM dynamic except for the NASA product.

(ii) The JAXA AMSR-E/AMSR2 products underestimate SM, while the ASCAT product overestimates it.

(iii) The SMOS product exhibits lots of noise and bias, and the LPRM AMSR-E product shows a significantly larger seasonal amplitude.

$\begin{array}{lll}\text { Zheng et al. } & \text { Maqu network, period } & \text { Noah LSM (Land Surface Model) simula- } \\ \text { (2015a) } & \text { between } 2009 \text { and } 2010 & \text { tions }\end{array}$

The modified hydraulic parameterization is able to resolve the SM underestimation in the upper soil layer under wet conditions, and it also leads to better capture for SM profile dynamics combined with the modified root distribution.

The SM simulated by the four LSMs can give reasonable SM dynamics but still show negative biases, probably resulting from the high soil organic carbon content.

(i) The standard and enhanced SMAP products have similar performance for SM spatial distributions.

(ii) The SM of enhanced SMAP product exhibits good agreement with the CLM4.5 SM simulation.

The model treating the surface SM as a second-order polynomial with LST, vegetation indices, and surface albedo outperforms other models.

The IEPFM (immune evolution particle filter with Markov chain Monte Carlo simulation) is able to mitigate particle impoverishment and provide better assimilation results. 
Table 1. Continued.

\begin{tabular}{llll}
\hline Literature & In situ data & Satellite- and/or model-based products & Key findings \\
\hline $\begin{array}{l}\text { Zheng et al. } \\
(2018 \mathrm{~b})\end{array}$ & $\begin{array}{l}\text { Ngari network, period } \\
\text { between 2015 and 2016 }\end{array}$ & SMAP Level 2 radiometer SM product & $\begin{array}{l}\text { Modifying surface roughness and employ- } \\
\text { ing soil temperature and texture informa- } \\
\text { tion can improve the SMAP SM retrievals } \\
\text { for the desert ecosystem of the TP. }\end{array}$ \\
\hline
\end{tabular}

\begin{tabular}{lll}
\hline Zhang et al. & Maqu and Ngari net- & ERA-Interim SM product, MERRA SM \\
(2018) & works, period between & product, GLDAS_Noah SM product (ver- \\
& 2010 and 2013 & sion 2.0 and version 2.1)
\end{tabular}

All these products exhibit overestimation in the Ngari network and underestimation in the Maqu network except for the ERAInterim product.

\begin{tabular}{lll}
\hline Zheng et al. & Maqu and Ngari net- & SMAP Level 1C radiometer brightness tem- \\
(2018a) & works, period between & perature products (version 3) \\
& 2015 and 2016
\end{tabular}

(i) The SMAP algorithm underestimates the significance of surface roughness while overestimating the impact of vegetation. (ii) The modified brightness temperature simulation can result in better SM retrievals.

\begin{tabular}{lll}
\hline $\begin{array}{l}\text { Wei et al. } \\
\text { (2019) }\end{array}$ & $\begin{array}{l}\text { Maqu and Ngari net- } \\
\text { works, period between } \\
2015 \text { and } 2016\end{array}$ & SMAP Level 3 SM passive product \\
\hline Liu et al. (2019) & $\begin{array}{l}\text { Maqu and Ngari net- } \\
\text { works, period between }\end{array}$ & SMAP Level 3 SM products (version \\
2012 and 2016 & $\begin{array}{l}\text { 105), Fengyun-3B Microwave Radiation } \\
\text { Image SM product (FY3B MWRI), JAXA }\end{array}$ \\
& & AMSR2 Level 3 SM product, LPRM \\
& AMSR2 Level 3 SM product (version 3.00)
\end{tabular}

The downscaled SM still can keep accuracy compared to the SM of the original SMAP product.

(i) The JAXA AMSR2 product underestimates area SM, while the LPRM AMSR2 product overestimates it.

(ii) The SMOS-IC product exhibits some noise of SM temporal variation.

(iii) The SMAP product has the highest accuracy among the five products, while FY3B shows relatively lower accuracy.

\begin{tabular}{lll}
\hline $\begin{array}{l}\text { Yang et al. } \\
(2020)\end{array}$ & $\begin{array}{l}\text { Maqu and Ngari net- } \\
\text { work, period between } \\
2008 \text { and } 2011\end{array}$ & AMSR-E brightness temperature product \\
& & \\
\hline Su et al. (2013) & $\begin{array}{l}\text { Maqu and Naqu net- } \\
\text { works, period between }\end{array}$ & $\begin{array}{l}\text { AMSR-E SM product, ASCAT Level 2 SM } \\
\text { product, ECMWF SM analyses products, } \\
\text { 2008 and 2009. }\end{array}$ \\
& $\begin{array}{l}\text { Kalman filter } \\
\text { Kalmum interpolation and extended }\end{array}$
\end{tabular}

The assimilated SM products exhibit higher accuracy than the AMSR-E product and LSM simulations for wet areas, whereas their accuracy is similar for dry areas.

(i) The Naqu area SM is overestimated by the ECMWF products in monsoon seasons, while the Maqu area SM produced by the ECMWF is comparable to previous studies. (ii) The SM estimate cannot be considerably improved by assimilating ASCAT data due to the CDF (cumulative distribution function) matching approach and the data quality.

\begin{tabular}{lll}
\hline $\begin{array}{l}\text { Zeng et al. } \\
(2016)\end{array}$ & $\begin{array}{l}\text { Maqu, Naqu and Ngari } \\
\text { networks, period be- } \\
\text { tween 2010 and 2011 }\end{array}$ & $\begin{array}{l}\text { LPRM AMSR-E SM product, ERA-Interim } \\
\text { SM product }\end{array}$ \\
\hline $\begin{array}{l}\text { Cheng et al. } \\
(2019)\end{array}$ & $\begin{array}{l}\text { Maqu, Naqu and Ngari } \\
\text { networks, period of } \\
2010\end{array}$ & $\begin{array}{l}\text { European Space Agency Climate Change } \\
\text { Initiative Soil Moisture SM product (ESA }\end{array}$ \\
& & CCISM version 4.4), ERA5 SM product
\end{tabular}

The blended SM is able to capture temporal variations across different climatic zones over the TP.

(i) The seasonal variation and spatial distribution of SM can be captured by all four products, i.e. ESA CCI_active, ESA CCI_passive, ESA CCI_combined, and ERA5.

(ii) The ESA CCI_active and ESA CCI_combined products exhibit narrower magnitude than the ESA CCI passive and ERA5 products.

(iii) The SM uptrend across the TP can be found from the ERA5 product. 


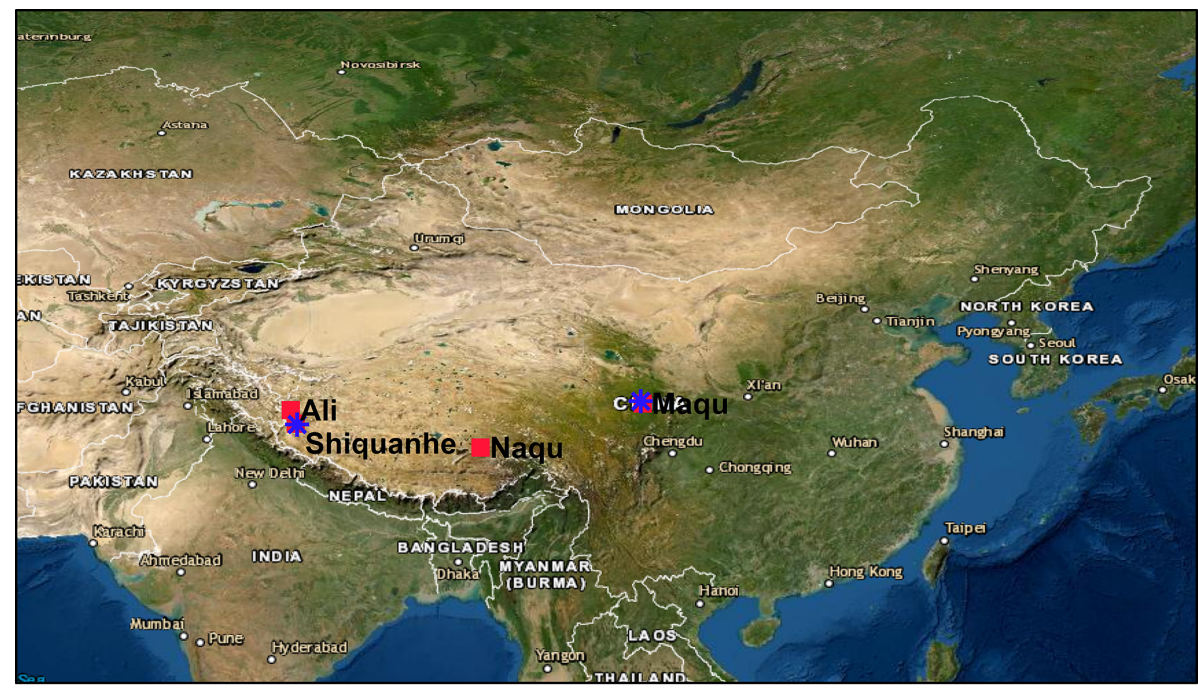

* CMA weather station

- Tibet-Obs network

Figure 1. Locations of the Tibet-Obs including Maqu, Naqu, and Ngari (including Ali and Shiquanhe) soil moisture monitoring networks. The weather stations of Maqu and Shiquanhe operated by the China Meteorological Administration (CMA) are also shown. (Base map is from Esri, Copyright: (C) Esri.)

\section{Data}

\subsection{Status of the Tibet-Obs}

The Tibet-Obs consists of the Maqu, Naqu, and Ngari (including Shiquanhe and Ali) regional-scale SMST monitoring networks (Fig. 1), which cover a cold humid climate, cold semi-arid climate, and cold arid climate, respectively. Each network includes a number of monitoring sites that measure the SMST at different soil depths. Brief descriptions of each network and corresponding surface SM measurements taken at a depth of $5 \mathrm{~cm}$ are given in the following subsections. The readers are referred to the existing literature (Su et al., 2011; Dente et al., 2012b; Zhao et al., 2018) for additional information on the networks.

\subsubsection{Maqu network}

The Maqu network is located in the north-eastern edge of the TP $\left(33^{\circ} 30^{\prime}-34^{\circ} 15^{\prime} \mathrm{N}, 101^{\circ} 38^{\prime}-102^{\circ} 45^{\prime} \mathrm{E}\right)$ at the first major bend of the Yellow River. The landscape is dominated by the short grass at elevations varying from 3400 to $3800 \mathrm{~m}$. The climate type is characterized as cold and humid with cold dry winters and rainy summers. The mean annual air temperature is about $1.2^{\circ} \mathrm{C}$, with $-10^{\circ} \mathrm{C}$ for the coldest month (January) and $11.7^{\circ} \mathrm{C}$ for the warmest month (July) (Zheng et al., 2015a). The annual precipitation is about $600 \mathrm{~mm}$, which falls mainly in the warm season (May-October).

The Maqu network covers an area of approximately $40 \mathrm{~km}$ by $80 \mathrm{~km}$ and originally consisted of 20 SMST monitoring sites installed in 2008 (Dente et al., 2012b). During the pe- riod between 2014 and 2016, eight new sites were installed due to the damage to several old monitoring sites caused by local people or animals. The basic information of each monitoring site is summarized in Table A1 (Su et al., 2011), and the typical characteristics of topography and land cover within the network are shown in Fig. 2 as well.

The Decagon 5TM ECH $\mathrm{TH}_{2} \mathrm{O}$ probes are used to measure the SMST at nominal depths of 5, 10, 20, 40, and $80 \mathrm{~cm}$ (Fig. 3). The 5TM probe is a capacitance sensor measuring the dielectric permittivity of soil, and the Topp equation (Topp et al., 1980 ) is used to convert the dielectric permittivity to the volumetric SM. The accuracy of the 5TM volumetric SM was improved via a soil-specific calibration performed under laboratory conditions for each soil type found in the Maqu area (Dente et al., 2012b), leading to a decrease in the root mean square error (RMSE) from 0.06 to $0.02 \mathrm{~m}^{3} \mathrm{~m}^{-3}$ (Dente et al., 2012b). Table 2 provides the specific periods of data missing during each year and the total data lengths of surface SM for each monitoring site. Among these sites, the CST05, NST01, and NST03 have collected more than 9 years of SM measurements, while the data records for the NST21, NST22, and NST31 are less than 1 year. In May 2019, there were still 12 sites that provided SM data.

\subsubsection{Ngari network}

The Ngari network is located in the western part of the TP at the headwater of the Indus River. It consists of two SMST networks established around the cities of Ali and Shiquanhe. The landscape is dominated by a desert ecosystem at elevations varying from 4200 to $4700 \mathrm{~m}$. The climate is character- 


\section{(a) Maqu}
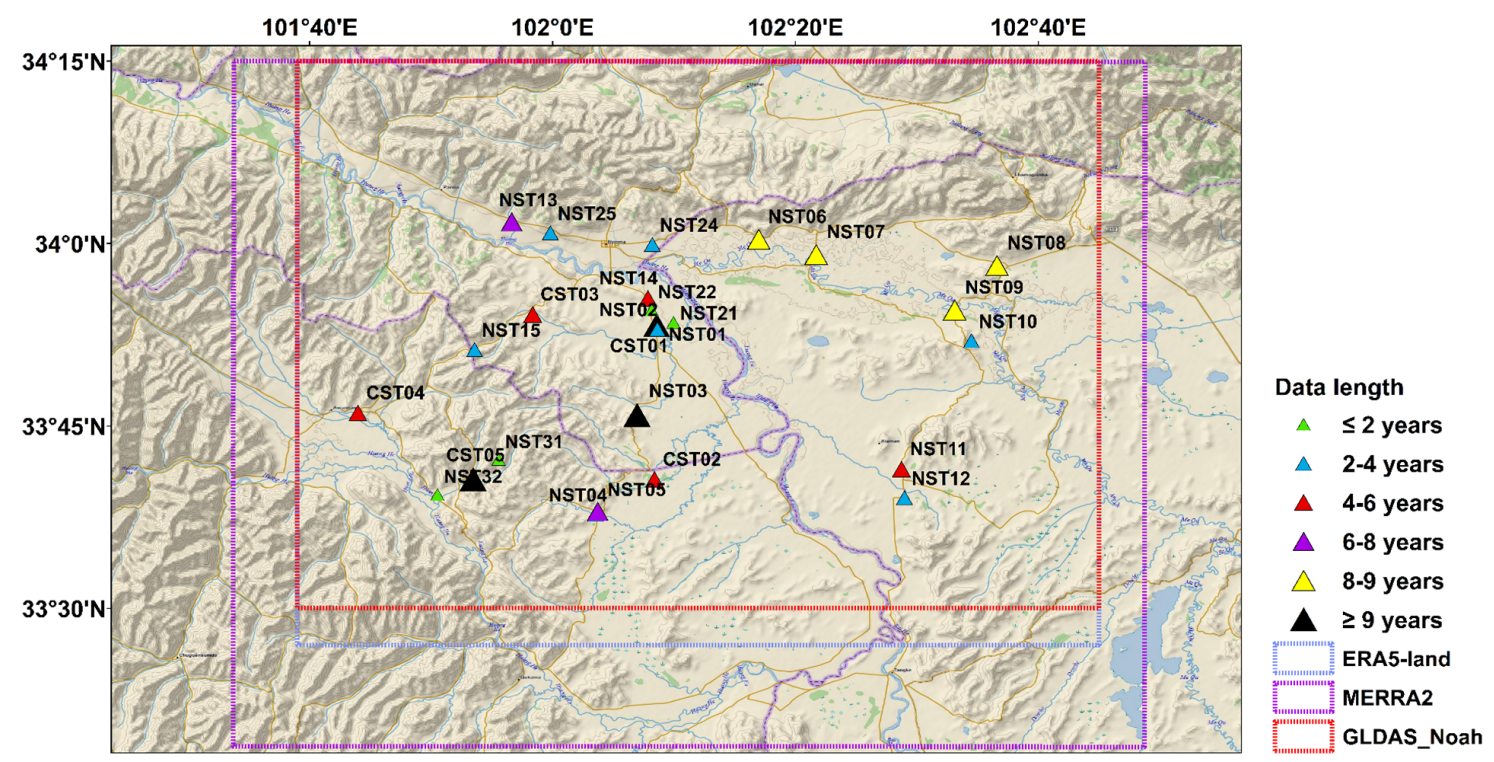

(b) River valley (NST02)

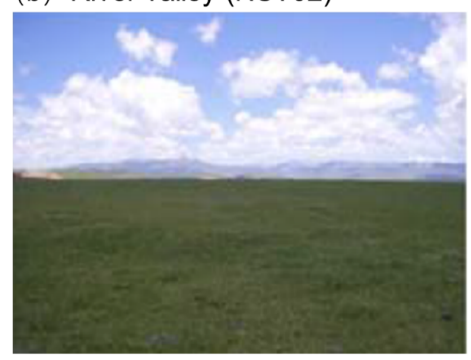

(e) Valley (NST13)

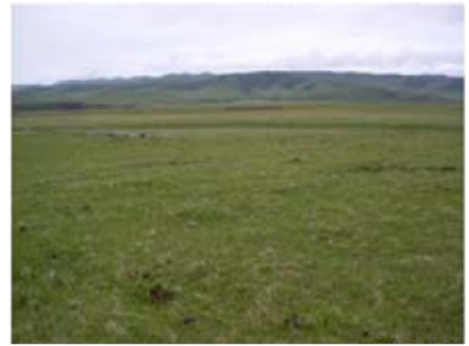

(c) Hill valley (CST04)

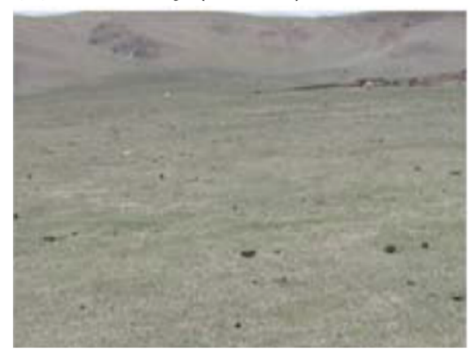

(f) Wetland (NST04)

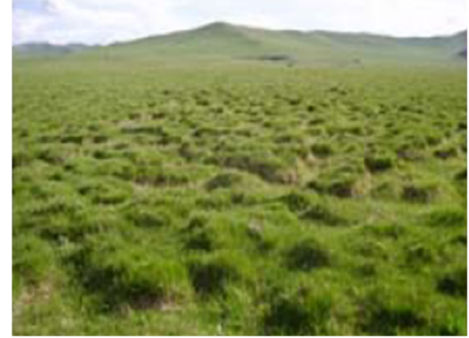

(d) Hill slope (NST15)

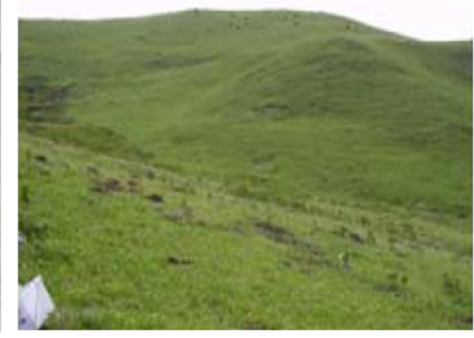

(g) Grass (NST09)

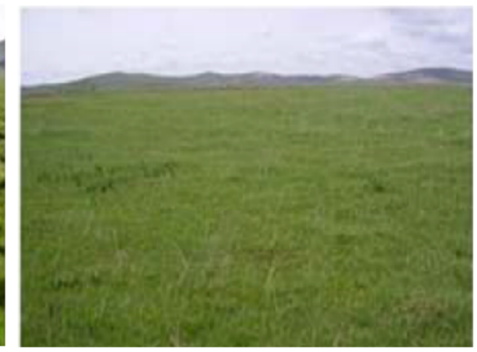

Figure 2. (a) Overview of the Maqu monitoring network, and typical characteristics of topography and land cover within the network: (b) river valley, (c) hill valley, (d) hill slope, (e) valley, (f) wetland, and (g) grass. The coloured triangles in panel (a) represent different data lengths of surface SM measurements for each site, and the coloured boxes represent the coverage of selected model-based products. The site name in brackets in panels (b-g) indicates the site location for which the photograph is selected. (Base map copyright: (C) 2018 Garmin.)

ized as cold and arid with a mean annual air temperature of $7.0^{\circ} \mathrm{C}$. The annual precipitation is less than $100 \mathrm{~mm}$, which falls mainly in the monsoon season (July-August) (van der Velde et al., 2014b).

The Shiquanhe network originally consisted of 16 SMST monitoring sites installed in 2010 (Su et al., 2011), and five new sites were installed in 2016. The basic information of each monitoring site is summarized in Table A3 ( $\mathrm{Su}$ et al.,
2011), and the typical characteristics of topography and land cover within the network are also shown in Fig. 4. The Decagon 5 TM ECH $\mathrm{EH}_{2} \mathrm{O}$ probes were installed at depths of 5, 10, 20, 40, and 60 or $80 \mathrm{~cm}$ to measure the SMST (Fig. 3). Table 3 provides the specific periods of data missing during each year and the total data lengths of surface SM for each site. Among these sites, the SQ02, SQ03, SQ06, and SQ14 have collected more than 8 years of SM measurements, while 
Table 2. Data records of all the SMST monitoring sites performed for the Maqu network. Blank cells represent that there are no measurements performed. Cells with a hyphen represent that data are available. The number in cells represents the month(s) when the data are missing during a year.

\begin{tabular}{|c|c|c|c|c|c|c|c|c|c|c|c|c|}
\hline & 2009 & 2010 & 2011 & 2012 & 2013 & 2014 & 2015 & 2016 & 2017 & 2018 & 2019 & $\begin{array}{r}\text { Data length } \\
\text { (months) }\end{array}$ \\
\hline CST01 & - & - & $10-12$ & $1-6,10-12$ & & & & & & & & 36 \\
\hline CST02 & - & - & $5-12$ & $1-10$ & 6 & $7-12$ & & & & & & 46 \\
\hline CST03 & - & - & - & - & $6-12$ & $1-10$ & $7-12$ & & & $1-9$ & $5-12$ & 68 \\
\hline CST04 & $1-5$ & - & 12 & $1-3,11,12$ & $1-2,6$ & $8-10$ & $7-12$ & & $1-6$ & $7-12$ & & 73 \\
\hline CST05 & - & - & - & - & 6 & - & - & $5-7$ & - & $1-2$ & $6-12$ & 119 \\
\hline NST01 & $1-5$ & - & - & - & 6 & - & - & $5-7$ & - & - & $6-12$ & 116 \\
\hline NST02 & $1-3$ & - & - & $7,8,10-12$ & & & & & & & & 40 \\
\hline NST03 & - & - & $5-10$ & - & 6 & - & - & $5-7$ & - & - & $6-12$ & 115 \\
\hline NST04 & - & - & $10-12$ & & & & & & & & & 33 \\
\hline NST05 & $3-5$ & - & - & - & $6-12$ & $1-7$ & - & $5-7$ & $7-12$ & $1-7$ & $6-12$ & 92 \\
\hline NST06 & - & $1-3,12$ & $1-3$ & - & 6 & - & - & 6,7 & 8-12 & $1-7$ & $6-12$ & 104 \\
\hline NST07 & - & - & 3 & - & 6,12 & 1 & 12 & $1,2,7,12$ & $1,2,12$ & $1-3,9-12$ & & 101 \\
\hline NST08 & - & $2,49-12$ & $1-5$ & - & $6-10$ & $1-10$ & - & 6,7 & - & - & $6-12$ & 95 \\
\hline NST09 & 1,12 & $1-4,12$ & $1-3$ & - & $1-2,6$ & $7-10$ & 12 & $1-3,7,12$ & $1,2,7$ & - & $6-12$ & 99 \\
\hline NST10 & - & $11-12$ & $1-57-12$ & $1-6$ & $6-12$ & & & & & $1-7$ & $6-12$ & 44 \\
\hline NST11 & - & - & - & $7-8$ & 6 & $7-12$ & & & & & & 63 \\
\hline NST12 & $10-12$ & $1-9$ & - & - & $6-12$ & $1-10$ & $7-12$ & & & & & 49 \\
\hline NST13 & - & - & - & - & 6 & - & $7-12$ & & & & & 77 \\
\hline NST14 & $6-9$ & - & - & - & 6 & $10-12$ & & & & & & 64 \\
\hline NST15 & - & $10-12$ & $1-5$ & $6-12$ & & & & & & & & 33 \\
\hline NST21 & & & & & & $1-7$ & $7-12$ & & & & & 11 \\
\hline NST22 & & & & & & $1-7$ & $7-12$ & & & & & 11 \\
\hline NST24 & & & & & & $1-7$ & $2-12$ & $1-7$ & - & - & $6-12$ & 40 \\
\hline NST25 & & & & & & $1-7$ & - & $2-12$ & $1-8$ & - & $6-12$ & 39 \\
\hline NST31 & & & & & & & & & $1-8$ & $7-12$ & & 10 \\
\hline NST32 & & & & & & & & & & $1-5$ & $6-12$ & 12 \\
\hline
\end{tabular}

(a) Maqu

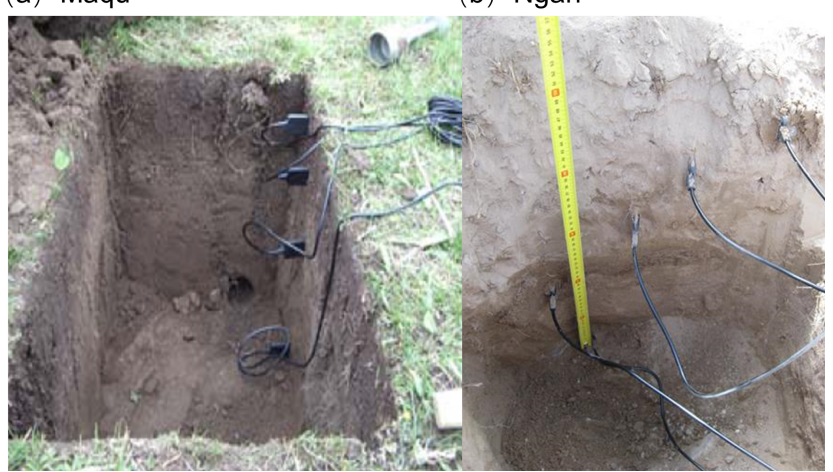

Figure 3. Examples of typical installation of sensors in monitoring sites of (a) Maqu and (b) Ngari networks.

the data records for the SQ13, SQ15, and SQ18 are less than 2 years. In August 2019, there were still 12 sites that provided SM data. The Ali network comprises four SM monitoring sites (Table A3), which will not be used for further analysis in this study due to limited number of monitoring sites and the availability of data records (Table 3 ).

\subsubsection{Naqu network}

The Naqu network is located in the Naqu River basin with an average elevation of $4500 \mathrm{~m}$. The climate is characterized as cold and semi-arid with cold dry winters and rainy summers. Over three-quarters of the total annual precipitation sum $(400 \mathrm{~mm})$ falls between June and August (Su et al., 2011). The landscape is dominated by short grass.

The network originally consisted of five SMST monitoring sites installed in 2006 (Su et al., 2011), and six new sites were installed between 2010 and 2016. The basic information of each monitoring site is summarized in Table A5, and the typical topography and land cover within the network are shown in Fig. 5 as well. The Decagon $5 \mathrm{TM} \mathrm{ECH}_{2} \mathrm{O}$ probes were installed at depths of 5 or $2.5,10$ or $7.5,15,30$, and $60 \mathrm{~cm}$ to measure the SMST, and an on-site soil-specific calibration is reported in van der Velde (2010) and yielded a RMSE of $0.029 \mathrm{~m}^{3} \mathrm{~m}^{-3}$. Table 4 provides the specific periods of data missing during each year and the total data lengths of surface $\mathrm{SM}$ for each site. Among these sites, only two sites (Naqu and MS sites in Table A5) have collected SM measurements for more than 6 years, while the data records for the others are less than 4 years. Similar to the Ali network, the Naqu network will also not be used for the further analysis in this 
(a) Shiquanhe

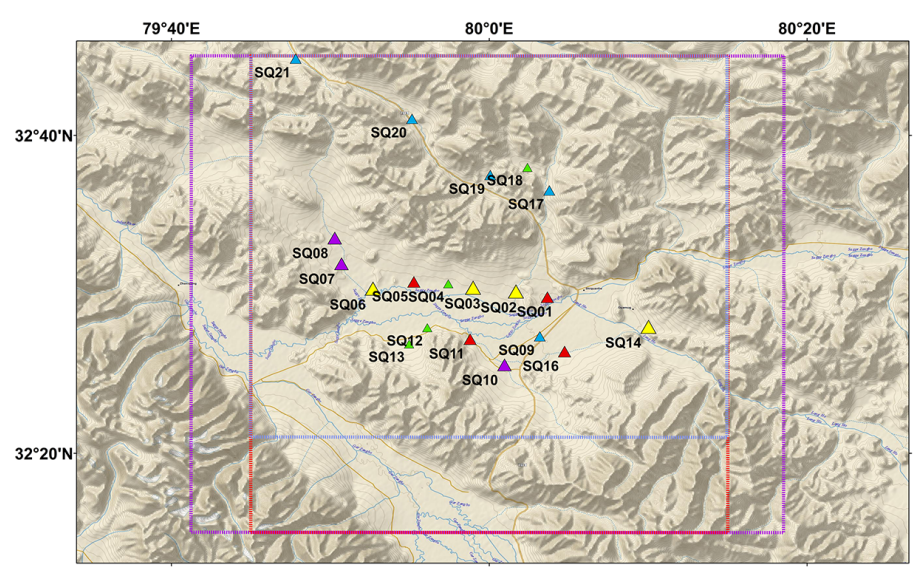

(c) Flat (SQ01)

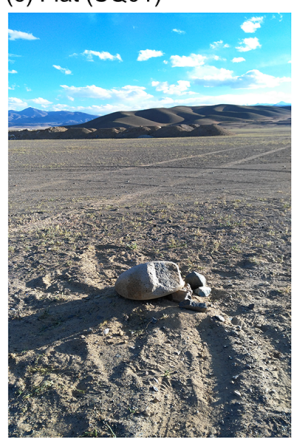

(d) Slope (SQ14)

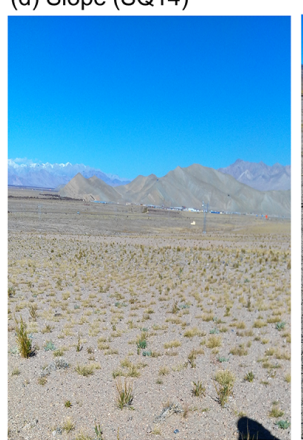

(b) Ali

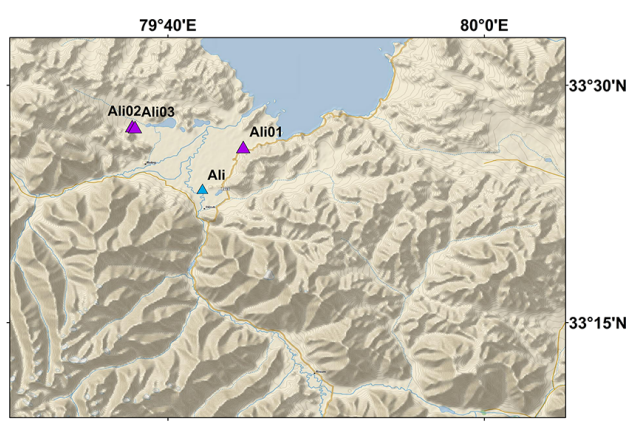
Data length
$\Delta \quad \leq 2$ years
$\triangle \quad 2-4$ years
$\Delta \quad 4-6$ years
4.8-8 years
$\triangle \quad$ 8-9 years

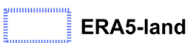
MERRA2
GLDAS_Noah

(e) Desert (SQ16)

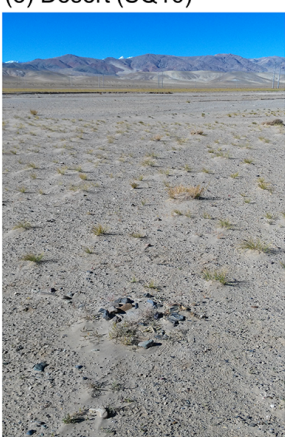

(f) Sparse grass (Ali03)

Figure 4. Overview of the Ngari monitoring network including (a) Shiquanhe and (b) Ali networks, and typical characteristics of topography and land cover within the network: (c) flat, (d) slope, (e) desert, and (f) sparse grass. The coloured triangles in panels (a, b) represent different data lengths of surface SM measurements for each site, and the coloured boxes represent the coverage of selected model-based products. The site name in brackets in panels (c-f) indicates the site location for which the photograph is selected. (Base map copyright: (C) 2018 Garmin.)

(a) Naqu

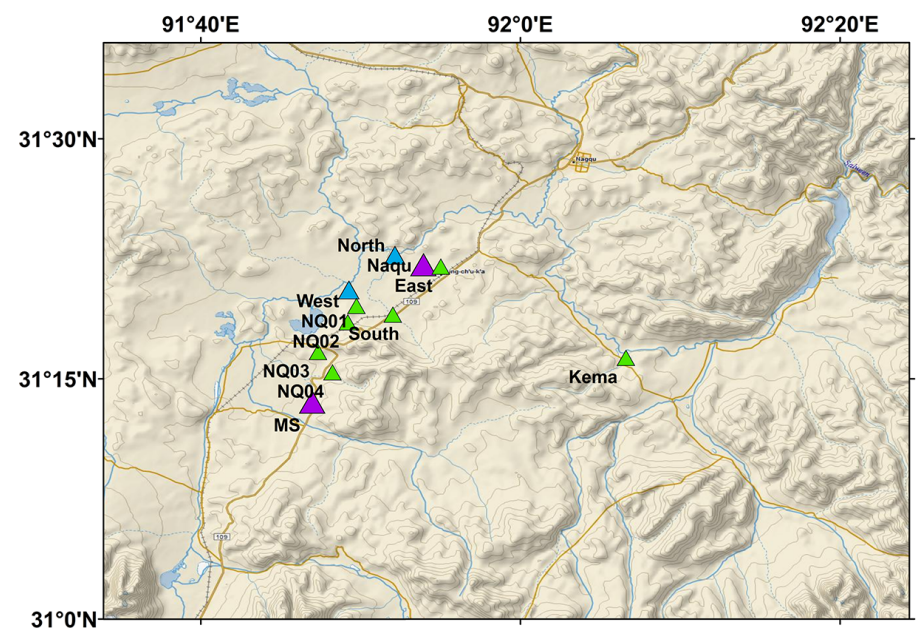

(b) Plain (West)

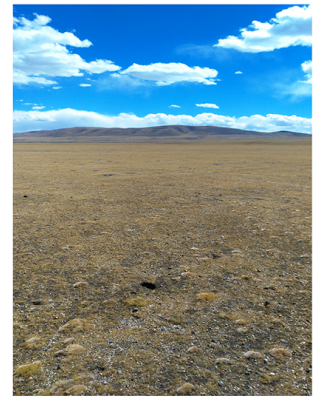

Data length

$\triangle \leq 2$ years

$\triangle 2-4$ years

$\triangle 4-6$ years

$\triangle 6-8$ years

Figure 5. (a) Overview of the Naqu monitoring network, and typical characteristics of topography and land cover within the network: (b) plain and (c) grassland. The coloured triangles in panel (a) represent different data lengths of surface SM measurements for each site. The site name in brackets in panels (b, c) indicates the site location for which the photograph is selected. (Base map copyright: () 2018 Garmin.) 
Table 3. Same as Table 2 but for the Ngari network.

\begin{tabular}{|c|c|c|c|c|c|c|c|c|c|c|c|}
\hline & 2010 & 2011 & 2012 & 2013 & 2014 & 2015 & 2016 & 2017 & 2018 & 2019 & Data length (months) \\
\hline \multicolumn{12}{|c|}{ Shiquanhe network } \\
\hline SQ01 & $1-7$ & - & - & - & $9-12$ & $1-9$ & & & & & 52 \\
\hline SQ02 & $1-7$ & - & - & - & $5-9$ & - & - & - & - & $9-12$ & 104 \\
\hline SQ03 & $1-7$ & - & - & - & $8-9$ & - & - & - & - & $9-12$ & 107 \\
\hline SQ04 & $1-7$ & - & $9-12$ & & & & & & & & 25 \\
\hline SQ05 & $1-7$ & - & - & - & $5-12$ & & & & & & 45 \\
\hline SQ06 & $1-7$ & - & $9-12$ & 1 & $2-9$ & - & - & - & - & $9-12$ & 96 \\
\hline SQ07 & $1-7$ & - & - & $9-12$ & $1-8$ & - & 7,8 & 7,8 & - & $9-12$ & 93 \\
\hline SQ08 & $1-7$ & $8-12$ & & $1-8$ & 8,9 & - & - & - & - & $9-12$ & 82 \\
\hline SQ09 & $1-7$ & - & $9-12$ & $1-8$ & $9-12$ & & & & & & 37 \\
\hline SQ10 & & $1-8$ & - & - & $7-12$ & $1-9$ & $7-12$ & $1-8$ & - & $9-12$ & 67 \\
\hline SQ11 & $1-7$ & - & - & $9-12$ & & & & & $1-8$ & $9-12$ & 49 \\
\hline SQ12 & $1-7$ & - & $9-12$ & & & & & & & & 25 \\
\hline SQ13 & $1-7$ & $8-12$ & & & & & & & & & 12 \\
\hline SQ14 & $1-7$ & - & - & - & $6,8,9$ & - & - & - & - & $9-12$ & 106 \\
\hline SQ16 & $1-7$ & $7-8$ & - & - & $3-8$ & $9-12$ & & & & & 53 \\
\hline SQ17 & & & & & & & $1-8$ & - & - & $9-12$ & 36 \\
\hline SQ18 & & & & & & & $1-8$ & 1 & $9-12$ & & 23 \\
\hline SQ19 & & & & & & & $1-8$ & - & - & $9-12$ & 36 \\
\hline SQ20 & & & & & & & $1-8$ & - & - & $9-12$ & 36 \\
\hline SQ21 & & & & & & & $1-8$ & - & - & $9-12$ & 36 \\
\hline \multicolumn{12}{|c|}{ Ali network } \\
\hline Ail & $1-7$ & - & $9-12$ & $1-8$ & & & & $1-8$ & $8-12$ & & 40 \\
\hline Ali01 & $1-7$ & $8-12$ & $1-8$ & - & 8 & - & - & - & $8-12$ & & 82 \\
\hline Ali02 & $1-7,11,12$ & $1-8$ & - & - & 8 & - & - & - & $8-12$ & & 85 \\
\hline Ali03 & $1-7$ & - & - & $3-12$ & $1-8$ & - & - & - & $8-12$ & & 78 \\
\hline
\end{tabular}

study due to limited number of monitoring sites and the availability of data records.

\subsection{Precipitation data}

Precipitation data are available from the dataset of daily climate data from Chinese surface meteorological stations. This dataset is maintained by the China Meteorological Administration (CMA) and based on the measurements from 756 basic and reference surface meteorological observation and automatic weather stations in China from 1951 to present. The online dataset mainly includes seven meteorological variables: air pressure, air temperature, relative humidity, wind speed, evaporation, sunshine duration, and precipitation. The precipitation data from two weather stations (see Fig. 1), i.e. Maqu $\left(34^{\circ} 0^{\prime} \mathrm{N}, 102^{\circ} 5^{\prime} \mathrm{E}\right.$ ) and Shiquanhe $\left(32^{\circ} 30^{\prime} \mathrm{N}, 80^{\circ} 5^{\prime} \mathrm{E}\right)$, are used in this study. The available daily precipitation is the cumulative value for the period between $20 \mathrm{~h}$ of the previous day and $20 \mathrm{~h}$ of the current day in Beijing time, which is available from https://data.cma.cn/data/detail/dataCode/SURF_ CLI_CHN_MUL_DAY.html (last access: 11 March 2021). The daily precipitation is summed up for each month to obtain the monthly cumulative value in this study, which can be found at https://doi.org/10.4121/12763700.v7 (Zhang et al., 2020). The monthly precipitation data for the period between 2009 and 2019 are mainly used in this study for the trend analysis (see Sect. 4.2).

\subsection{Model-based soil moisture products}

\subsubsection{ERA5-Land soil moisture product}

ERA5-Land is a reanalysis dataset produced by running the land component of the ECMWF (European Centre for Medium-Range Weather Forecasts) ERA5 climate model (Albergel et al., 2018). ERA5-Land provides SM data currently available from 1981 to present for every hour with a spatial resolution of $0.1^{\circ}$, and the data are available from https://cds.climate.copernicus.eu/cdsapp\# !/dataset/reanalysis-era5-land?tab (last access: 11 March 2021). For more information about the ERA5-Land product, readers are referred to Muñoz-Sabater et al. (2018). The data of volumetric total soil water content for the top soil layer $(0-7 \mathrm{~cm})$ are used in this study. 
Table 4. Same as Table 2 but for the Naqu network.

\begin{tabular}{|c|c|c|c|c|c|c|c|c|c|c|c|}
\hline & 2010 & 2011 & 2012 & 2013 & 2014 & 2015 & 2016 & 2017 & 2018 & 2019 & Data length (months) \\
\hline Naqu & $1-7$ & - & - & 8,9 & $6-8$ & $6-9$ & - & $9-12$ & $1-8$ & $9-12$ & 88 \\
\hline East & & $1-8$ & - & $9-12$ & & & & & & & 24 \\
\hline West & $1-7$ & $1-8$ & - & $1-9$ & $7-12$ & $1-7$ & $8-12$ & & & & 42 \\
\hline North & & $1-8,11,12$ & $1-3,9$ & $9-12$ & & & $1-8$ & $9-12$ & $1-8$ & $9-12$ & 42 \\
\hline South & & $1-8$ & $9-12$ & & & & & & & & 12 \\
\hline Kema & & & & $1-9$ & 3-9 & - & $8-12$ & & & & 26 \\
\hline MS & $1-7$ & - & $10-12$ & $1-9$ & $8,9,11,12$ & $1-5$ & - & $9-12$ & $1-8$ & $9-12$ & 76 \\
\hline NQ01 & & & & & & & & & $1-8$ & $9-12$ & 12 \\
\hline NQ02 & & & & & & & & & $1-8$ & $9-12$ & 12 \\
\hline NQ03 & & & & & & & $1-8$ & $9-12$ & $1-8$ & $9-12$ & 24 \\
\hline NQ04 & & & & & & & & & $1-8$ & $9-12$ & 12 \\
\hline
\end{tabular}

\subsubsection{MERRA2 soil moisture product}

MERRA2 is an atmospheric reanalysis dataset produced by NASA using the Goddard Earth Observing System Model version 5 (GEOS-5) and Atmospheric Data Assimilation System (ADAS) version 5.12.4. MERRA2 provides SM data currently available from 1980 to present at a hourly time interval and spatial resolution of $0.5^{\circ}$ (latitude) by $0.625^{\circ}$ (longitude). The data are available from https://disc. gsfc.nasa.gov/datasets/M2T1NXLND_5.12.4/summary (last access: 11 March 2021). For more information about the MERRA2 product, readers are referred to GMAO (2015). The liquid volumetric soil water content of the surface layer $(0-5 \mathrm{~cm})$ is used in this study.

\subsubsection{GLDAS Noah soil moisture product}

GLDAS-2.1 Noah is a combination of model-based and satellite-observed meteorological data, such as data from the Global Precipitation Climatology Project (GPCP) version 1.3 forced onto the Noah Land Surface Model 3.6 in Land Information System (LIS) version 7 to simulate water and energy exchanges between land and atmosphere. GLDAS-2.1 Noah provides SM data currently available from 2000 to present at a 3-hourly time interval with a spatial resolution of $0.25^{\circ}$. The data are available from https://disc.gsfc.nasa.gov/ datasets/GLDAS_NOAH025_3H_2.1/summary (last access: 11 March 2021). More details on the GLDAS Noah product can be found in Rodell et al. (2004). The liquid soil water content of the top soil layer $(0-10 \mathrm{~cm})$ is used in this study.

\section{Methods}

\subsection{Spatial upscaling of soil moisture measurements}

The principle of spatial upscaling a set of point measurements to an area is based on assigning weights to individual sites, often using additional information, in such a way that the selected collection is representative for the selected domain. The method can in its simplest form be represented by a linear equation mathematically as follows:

$\overline{\boldsymbol{\theta}}_{t}^{\mathrm{ups}}=\boldsymbol{\theta}_{t}^{\mathrm{obs}} \boldsymbol{\beta}$,

$\boldsymbol{\theta}_{t}^{\mathrm{obs}}=\left[\theta_{t, 1}^{\mathrm{obs}}, \theta_{t, 2}^{\mathrm{obs}}, \ldots, \theta_{t, n}^{\mathrm{obs}}\right]^{T}$,

where $\theta_{t}^{\text {ups }}\left(\mathrm{m}^{3} \mathrm{~m}^{-3}\right)$ represents the upscaled SM, $\boldsymbol{\theta}_{t}^{\text {obs }}$ $\left(\mathrm{m}^{3} \mathrm{~m}^{-3}\right)$ represents the vector of SM measurements, $N$ represents the total number of SM monitoring sites, $t$ represents the time (e.g. the $t$ th day), and $\boldsymbol{\beta}(-)$ represents the vector with weights.

In this study, only the surface SM measurements taken from the Maqu and Shiquanhe networks are upscaled to obtain the regional-scale SM for 10-year (2009-2019) periods due to the availability of much longer records in comparison to the Naqu and Ali networks (see Sect. 2.1). Four upscaling methods are investigated and inter-compared with each other to find the most suitable method for the application to the Tibet-Obs. Brief descriptions of the selected upscaling methods are given in Appendix B. The arithmetic average (hereafter "AA") assigns an equal weight coefficient to each SM monitoring site (see Appendix B.1), and the Voronoi diagram (hereafter "VD") determines the weight based on the geographic distribution of all the SM monitoring sites (see Appendix B.2). The time stability method (hereafter "TS") regards the most stable site as representative for the network (see Appendix B.3), and the apparent thermal inertia (ATI) method is based on the close relationship between apparent thermal inertia $(\tau)$ and SM (see Appendix B.4).

\subsection{Trend analysis}

The Mann-Kendall test and Sen's slope estimate (Gilbert, 1987; Mann, 1945) are adopted to analyse the trend of the 10-year time series for the upscaled SM, model-based SM products (i.e. ERA5-Land, GLDAS Noah, and MERRA2), and precipitation. Specifically, the trend analysis is based on the monthly data, and all the missing data are regarded as an equal value smaller than other valid data. The test consists of calculating the seasonal statistics $S$ and their variance 
$\operatorname{VAR}(S)$ separately for each month during the 10-year period, and the seasonal statistics are then summed to obtain the $Z$ metric.

For month $i$ (e.g. January), the statistics $S_{i}$ can be computed as

$$
\begin{aligned}
& S_{i}=\sum_{k=1}^{9} \sum_{l=k+1}^{10} \operatorname{sgn}\left(X_{i, l}-X_{i, k}\right), \\
& \operatorname{sgn}\left(X_{i, l}-X_{i, k}\right)=\left\{\begin{array}{ll}
1, & X_{i, l}>X_{i, k} \\
0, & X_{i, l}=X_{i, k} \\
-1, & X_{i, l}<X_{i, k}
\end{array},\right.
\end{aligned}
$$

where $k$ and $l$ represent the different year and $l>k ; X_{i, l}$ and $X_{i, k}$ represent the monthly value of the variable for the month $i$ of the year $k$ and $l$, respectively.

The $\operatorname{VAR}\left(S_{i}\right)$ is computed as

$$
\begin{aligned}
\operatorname{VAR}\left(S_{i}\right)= & \frac{1}{18}\left[N_{i}\left(N_{i}-1\right)\left(2 N_{i}+5\right)\right. \\
& \left.-\sum_{p=1}^{g_{i}} t_{i, p}\left(t_{i, p}-1\right)\left(2 t_{i, p}+5\right)\right],
\end{aligned}
$$

where $N_{i}$ is the length of the record for the month $i$ (e.g. the 10-year data record in this study with $N_{i}=10$ ); $g_{i}$ is the number of equal-value data in month $i$; and $t_{i, p}$ is the number of equal-value data in the $p$ th group for month $i$.

After obtaining the $S_{i}$ and $\operatorname{VAR}\left(S_{i}\right)$, the statistics $S^{\prime}$ and $\operatorname{VAR}\left(S^{\prime}\right)$ for the selected season (e.g. warm season is from May up to October, and cold season is from November to April) can be summed as

$$
S^{\prime}=\sum_{i=1}^{M} S_{i},
$$

$\operatorname{VAR}\left(S^{\prime}\right)=\sum_{i=1}^{M} \operatorname{VAR}\left(S_{i}\right)$,

where $M$ represents the number of months in the selected season (e.g. $M$ is 12 for the full year, and $M$ is 6 for the warm and cold seasons).

Subsequently, the $Z$ metric can be computed as

$Z=\left\{\begin{array}{ll}\frac{S^{\prime}-1}{\sqrt{\operatorname{VAR}\left(S^{\prime}\right)}}, & \text { if } S^{\prime}>0 \\ 0, & \text { if } S^{\prime}=0 \\ \frac{S^{\prime}+1}{\sqrt{\operatorname{VAR}\left(S^{\prime}\right)}}, & \text { if } S^{\prime}<0\end{array}\right.$.

If the $Z$ metric is positive (negative) and its absolute value is greater than $Z_{1-\alpha / 2}$ (here $\alpha=0.05, Z_{1-\alpha / 2}=1.96$ ), the trend of the time series is regarded as upward (downward) at the significance level of $\alpha$. Otherwise, we accept the hypothesis that no significant trend is found.

If the trend appears upward or downward, we will further estimate the slope (change per unit time) with Sen's method
(Sen, 1968). The slopes of each month can be calculated as

$Q_{i}=\frac{X_{i, l}-X_{i, k}}{l-k}$.

We then rank all the individual slopes $\left(Q_{i}\right)$ for all months and find the median, which is considered as the seasonal Kendall slope estimate.

\subsection{Comparison metrics}

The metrics used to evaluate the accuracy of the upscaled SM are the bias $\left(\mathrm{m}^{3} \mathrm{~m}^{-3}\right)$, RMSE $\left(\mathrm{m}^{3} \mathrm{~m}^{-3}\right)$, and unbiased RMSE (ubRMSE $\left(\mathrm{m}^{3} \mathrm{~m}^{-3}\right)$ ), which can be formulated as

$$
\begin{aligned}
& \text { bias }=\frac{\sum_{t=1}^{M}\left(\boldsymbol{\theta}_{t}^{\mathrm{tru}}-\overline{\boldsymbol{\theta}}_{t}^{\mathrm{ups}}\right)}{M}, \\
& \text { RMSE }=\sqrt{\frac{\sum_{t=1}^{M}\left(\boldsymbol{\theta}_{t}^{\mathrm{tru}}-\overline{\boldsymbol{\theta}}_{t}^{\mathrm{ups}}\right)^{2}}{M},} \\
& \text { ubRMSE }=\sqrt{\mathrm{RMSE}^{2}-\mathrm{bias}^{2}},
\end{aligned}
$$

where $\boldsymbol{\theta}_{t}^{\text {tru }}$ represents the SM that is considered as the ground truth, and $\overline{\boldsymbol{\theta}}_{t}^{\mathrm{ups}}$ represents the upscaled SM. The closer the metric is to zero, the more accurate the estimation is.

The metric used to assess the correlation between two time series is the Nash-Sutcliffe efficiency coefficient (NSE (-)), expressed by

$\mathrm{NSE}=1-\frac{\sum_{t=1}^{n}\left(\boldsymbol{\theta}_{t}^{\mathrm{tru}}-\overline{\boldsymbol{\theta}}_{t}^{\mathrm{ups}}\right)^{2}}{\sum_{t=1}^{n}\left(\boldsymbol{\theta}_{t}^{\mathrm{tru}}-\overline{\boldsymbol{\theta}_{t}^{\mathrm{tru}}}\right)^{2}}$.

The value of the NSE ranges from $-\infty$ to 1 , and the closer the metric is to 1 , the better the match of the estimated SM with the reference $\left(\boldsymbol{\theta}_{t}^{\mathrm{tru}}\right)$.

The metric used to define the most representative SM time series (i.e. the best upscaled SM) is the comprehensive evaluation criterion (CEC (-)) obtained by combining the mean relative difference (MRD (-)) and standard deviation of the relative difference $(\sigma(\mathrm{RD})(-))$ (Jacobs et al., 2004). Detailed description of the above-mentioned three metrics are given in Appendix B.3. It should be noted that the $\boldsymbol{\theta}_{t, i}^{\mathrm{obs}}$ and $\overline{\boldsymbol{\theta}_{t}^{\mathrm{obs}}}$ in Eqs. (B4) and (B5) represent the upscaled SM using four different methods and their average when using the CEC to determine the best upscaled SM. The most representative time series is identified by the lowest CEC value.

\subsection{Preprocessing of model-based soil moisture products}

The performance of the ERA5-Land, MERRA2, and GLDAS Noah SM products are assessed using the upscaled SM data of the Maqu and Shiquanhe networks for a 10-year period. The corresponding regional-scale SM for each product has 
been obtained by averaging the data from all the grid cells falling in the respective network areas. The numbers of grid cells covering the Maqu and Shiquanhe networks are 77 and 20 for the ERA5-Land product, 12 and 4 for the GLDAS Noah product, and only 1 for the MERRA2 product. For the ERA5-Land and MERRA2 products the data available at hourly and 3-hourly time steps are averaged to a daily value, and the units of GLDAS Noah SM are converted from $\mathrm{kg} \mathrm{m}^{-2}$ to $\mathrm{m}^{3} \mathrm{~m}^{-3}$. Further it should be noted that the uppermost soil layer of the ERA5-Land $(0-7 \mathrm{~cm})$, MERRA2 $(0-5 \mathrm{~cm})$, and GLDAS Noah $(0-10 \mathrm{~cm})$ SM products are assumed to match the in situ observations at depth of $5 \mathrm{~cm}$ considering the $4 \mathrm{~cm}$ influence zone found under laboratory conditions for the 5TM sensor by Benninga et al. (2018).

\section{Results}

\subsection{Inter-comparison of soil moisture upscaling methods}

In this section, four upscaling methods (see Sect. 3.1) are inter-compared first with the input of the maximum number of available SM monitoring sites for a single year in the Maqu and Shiquanhe networks to find the most suitable upscaled SM that can best represent the areal conditions (i.e. ground truth, $\mathrm{SM}_{\text {truth }}$ ). Later on, the performance of the four upscaling methods is further investigated with the input of a reduced number of SM monitoring sites to find the most suitable method for producing long-term $(\sim 10$-year) upscaled SM for the Maqu and Shiquanhe networks.

Figure 6 shows the time series of daily average SM for the Maqu and Shiquanhe networks produced by the four upscaling methods based on the maximum number of available SM monitoring sites (hereafter "SM$M_{A A-m a x}$ ", "SMVD-max", "SM TS-max", and "SM $_{\text {ATI-max }}$ "). Two different periods are selected for the two networks due to the fact that the number of available monitoring sites reaches the maximum in different periods for the two networks, e.g. 17 sites for Maqu between November 2009 and October 2010 and 12 sites for Shiquanhe between August 2018 and July 2019 (see Tables A2 and A4 in Appendix A). For the Maqu network, the SMAA-max, $\mathrm{SM}_{\mathrm{VD}-\max }$, and $\mathrm{SM}_{\mathrm{TS}-\max }$ are comparable to each other, while the $\mathrm{SM}_{\text {ATI-max }}$ deviates substantially during the winter (between December and February) and summer periods (between June and August). On the other hand, the $\mathrm{SM}_{\text {ATI-max }}$ for the Shiquanhe network is comparable to $\mathrm{SM}_{\mathrm{AA}-\max }$ and $\mathrm{SM}_{\mathrm{VD}-\mathrm{max}}$, while $\mathrm{SM}_{\mathrm{TS}-\max }$ 's behaviour is clearly different from the others. It seems that the ATI method performs better in the Shiquanhe network due to the existence of a stronger relationship between $\tau$ and $\theta$ in the desert ecosystem.

Table B1 lists the values of MRD (see Eq. B4 in Appendix B), $\sigma(\mathrm{RD})$ (Eq. B3), and CEC (Eq. B6) calculated for the upscaled SM produced by the four upscaling methods. The CEC is used here to determine the most suitable upscaled SM that can best represent the areal conditions for the two networks. It can be found that the SMAA-max con- sistently yields the lowest CEC values for both networks, indicating that the $\mathrm{SM}_{\mathrm{AA}-\max }$ can be used to represent actual areal conditions, which will thus be regarded as the ground truth for the following analysis (i.e. $\mathrm{SM}_{\text {truth }}$ ). The arithmetic average of the dense in situ measurements was also used as the ground truth in other studies (Qin et al., 2013; Su et al., 2013) and was found to yield reliable results by van der Velde et al. (2021).

As shown in Tables A2 and A4 (see Appendix A), the number of available SM monitoring sites decreased as time progressed. There are only three (i.e. CST05, NST01, and NST03) and four (i.e. SQ02, SQ03, SQ06, and SQ14) monitoring sites that provided more than 9 years of in situ SM measurement data for the Maqu and Shiquanhe networks, respectively (see Tables 2 and 3). This indicates that the minimum number of available monitoring sites can be used to produce the long-term $(\sim 10$-year) consistent upscaled SM is three and four for the Maqu and Shiquanhe networks, respectively. Figure 7 shows the daily average SM time series produced by the four upscaling methods based on the minimum available monitoring sites (hereafter "AA-min", "TSmin", "VD-min", and "ATI-min"). The $\mathrm{SM}_{\text {truth }}$ obtained by the AA-max is also shown for comparison purposes. For the Maqu network, the upscaled SM produced by the AA-min, VD-min, and TS-min generally capture well the $\mathrm{SM}_{\text {truth }}$ variations, while the upscaled SM of the ATI-min shows dramatic deviations. Similarly, the upscaled SM produced by the AA-min and VD-min are consistent with the $\mathrm{SM}_{\text {truth }}$ for the Shiquanhe network with slight overestimations, while significant deviations are noted for the upscaled SM of the TSmin and ATI-min. Table B2 lists the error statistics (e.g. bias, RMSE, ubRMSE, and NSE) computed between the upscaled SM produced by these four upscaling methods with the input of the minimum available sites and the $\mathrm{SM}_{\text {truth }}$. The upscaled SM produced by the AA-min shows better performance for both networks as indicated by the lower RMSE and higher NSE values in comparison to the other three upscaling methods.

Apart from the maximum and minimum number of available SM monitoring sites mentioned above, there are about $14,10,8$, and 6 available monitoring sites during different time spans for the Maqu network, and for the Shiquanhe network there are about $11,10,6$, and 5 available monitoring sites (see Tables A2 and A4 in Appendix A). Figure B2 shows the radar diagram of error statistics (i.e. RMSE and NSE) computed between the $\mathrm{SM}_{\text {truth }}$ and the upscaled SM produced by the four upscaling methods for different numbers of available monitoring sites. For the Maqu network, the performances of the AA and VD methods are better than the TS and ATI methods as indicated by smaller RMSEs and higher NSEs for all the estimations. A similar conclusion can be drawn for the Shiquanhe network, while the performance of the ATI method is largely improved when the number of available monitoring sites is not less than 10 . It is interesting to note that the upscaled SM produced by the AA-min is 
(a) Maqu

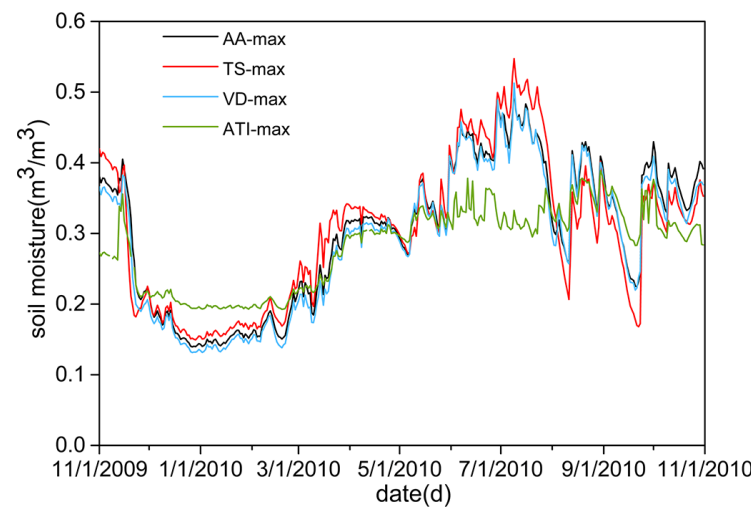

(b) Shiquanhe

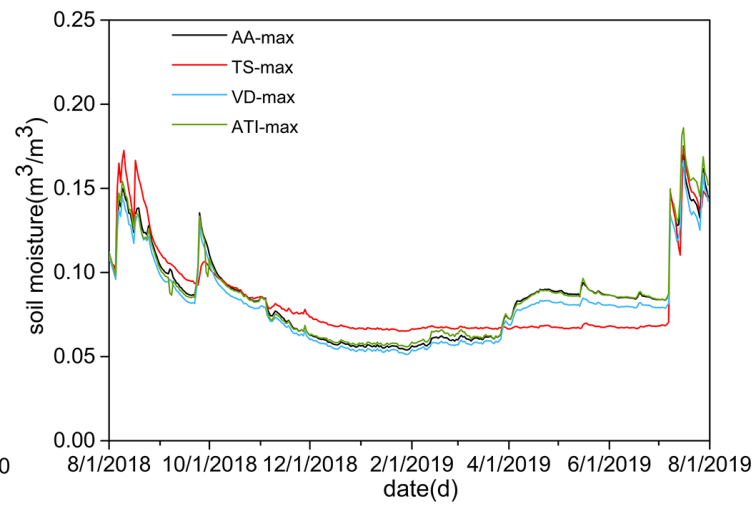

Figure 6. Comparisons of daily average SM for the (a) Maqu and (b) Shiquanhe networks produced by four upscaling methods with input of the maximum number of available SM monitoring sites. The date format is month/day/year.
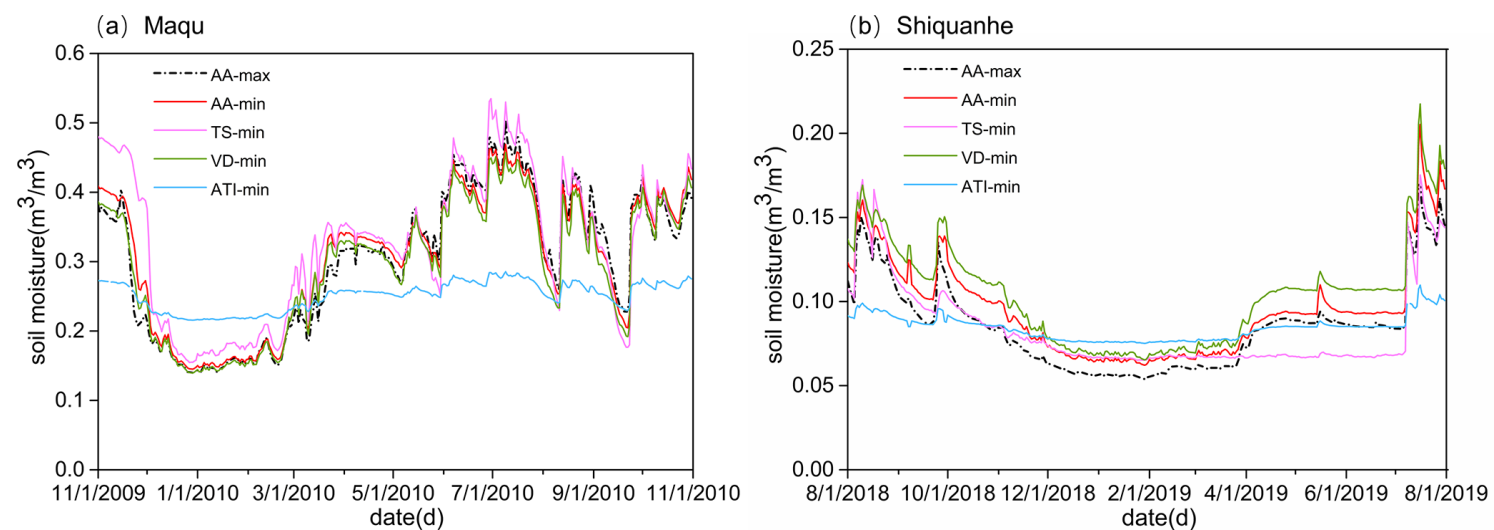

Figure 7. Comparisons of daily average SM for the (a) Maqu and (b) Shiquanhe networks produced by four upscaling methods with input of the minimum number of available SM monitoring sites. The date format is month/day/year.

comparable to those obtained with more sites (e.g. 10 sites) as indicated by comparable RMSE and NSE values for both networks. It indicates that the AA-min is suitable to produce long-term $(\sim 10$-year $)$ upscaled SM for both networks, which yield RMSEs of 0.022 and $0.011 \mathrm{~m}^{3} \mathrm{~m}^{-3}$ for the Maqu and Shiquanhe networks in comparison to the $\mathrm{SM}_{\text {truth }}$ produced by the AA-max based on the maximum available monitoring sites.

\subsection{Long-term analysis of upscaled soil moisture measurements}

In this section, the AA-min is first adopted to produce the consecutive upscaled SM time series (hereafter "SM $\mathrm{AA}-\min$ ") for approximately a 10-year period for the Maqu and Shiquanhe networks. In addition, the other time series of upscaled SM are produced by the AA method with input of all available SM monitoring sites regardless of the continu-

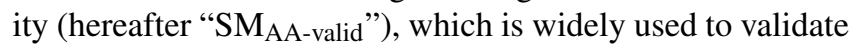
the various SM products (Dente et al., 2012b; Chen et al., 2013; Zheng et al., 2018b) for short periods (e.g. $\leq 2$ years).
This method may, however, lead to inconsistent SM time series for a long-term period due to the fact that the number of available sites is different in distinct periods (see Tables A2 and A4 in Appendix A). Trend analyses (see Sect. 3.2) are applied to both $\mathrm{SM}_{\mathrm{AA}-\mathrm{min}}$ and $\mathrm{SM}_{\mathrm{AA} \text {-valid }}$ to investigate the impact of changes of available SM monitoring sites on the long-term (i.e. 10-year) trend.

Figure 8a shows the time series of $\mathrm{SM}_{\mathrm{AA}-\mathrm{min}}$ and $\mathrm{SM}_{\mathrm{AA} \text {-valid }}$ along with the daily precipitation data for the Maqu network during the period between May 2009 and May 2019. The two time series of the SM show similar seasonality, with low values in winter due to frozen soils and high values in summer due to rainfall (see subplot of Fig. 8a). Deviations can be found between the $\mathrm{SM}_{\mathrm{AA}-\min }$ and

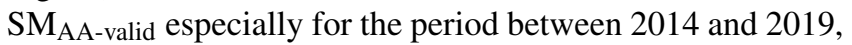
whereby the $\mathrm{SM}_{\mathrm{AA} \text {-valid }}$ tends to produce smaller SM values in the warm season. Figure 9a shows further the MannKendall trend test and Sen's slope estimate for the $\mathrm{SM}_{\mathrm{AA}-\mathrm{min}}$, $\mathrm{SM}_{\mathrm{AA}-\mathrm{valid}}$, and precipitation of the Maqu network area for the full year, warm seasons, and cold seasons in a 10-year period. As described in Sect. 3.2, the time series would present 
(a) Maqu

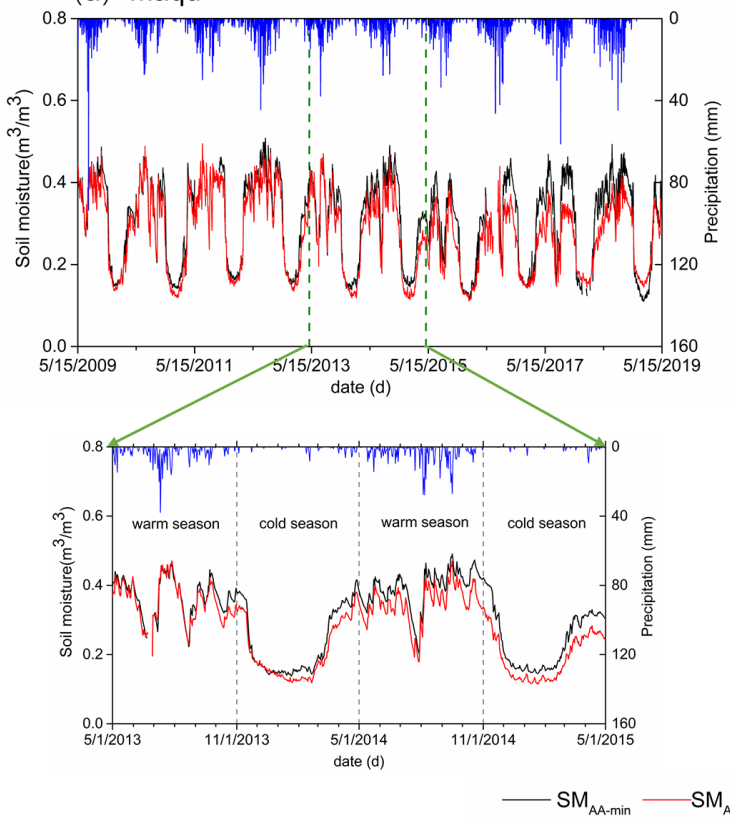

(b) Shiquanhe

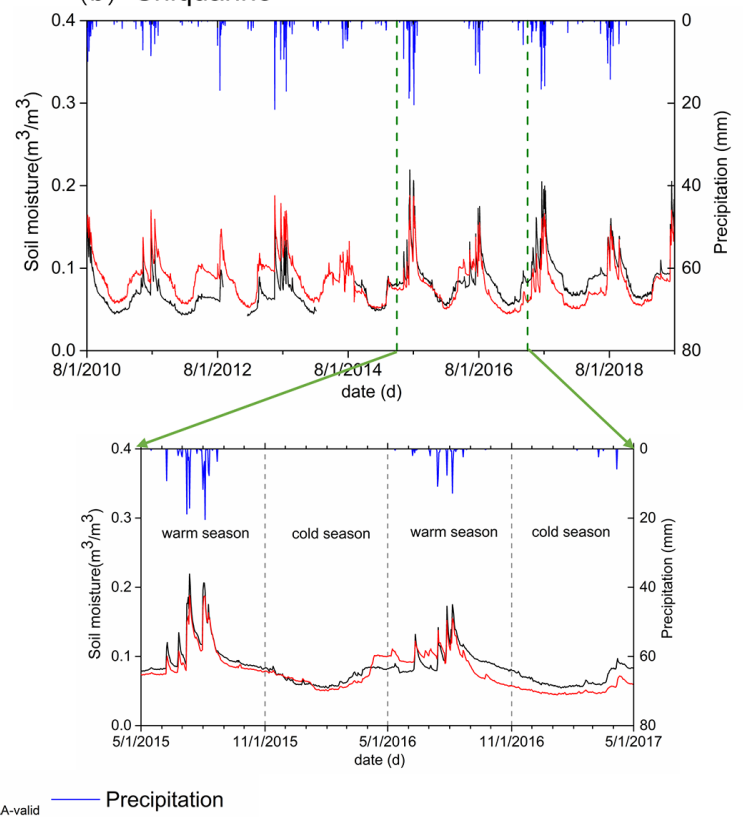

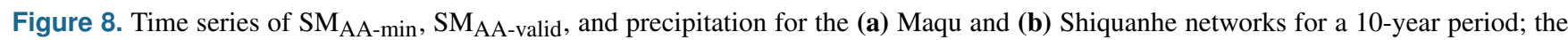
subplot highlights a 2-year period. The date format is month/day/year.

(a) Maqu

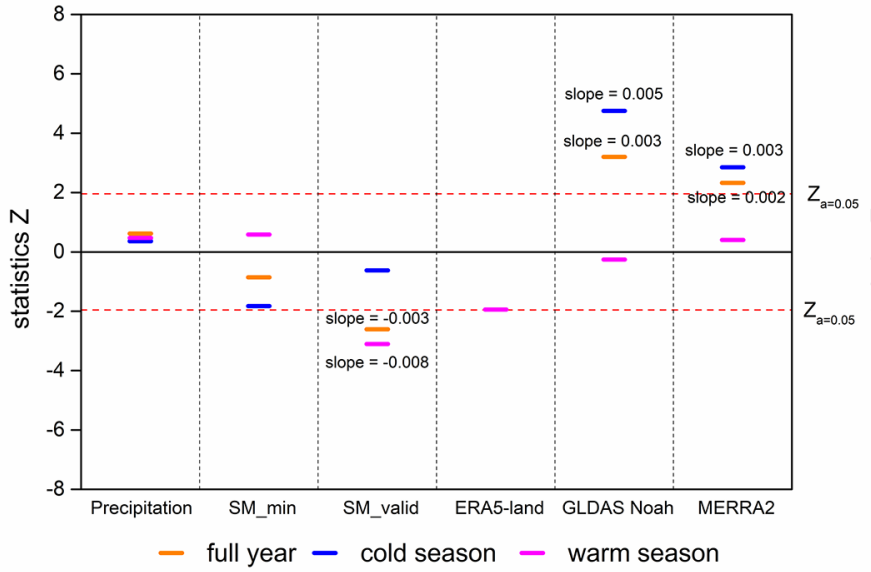

(b) Shiquanhe

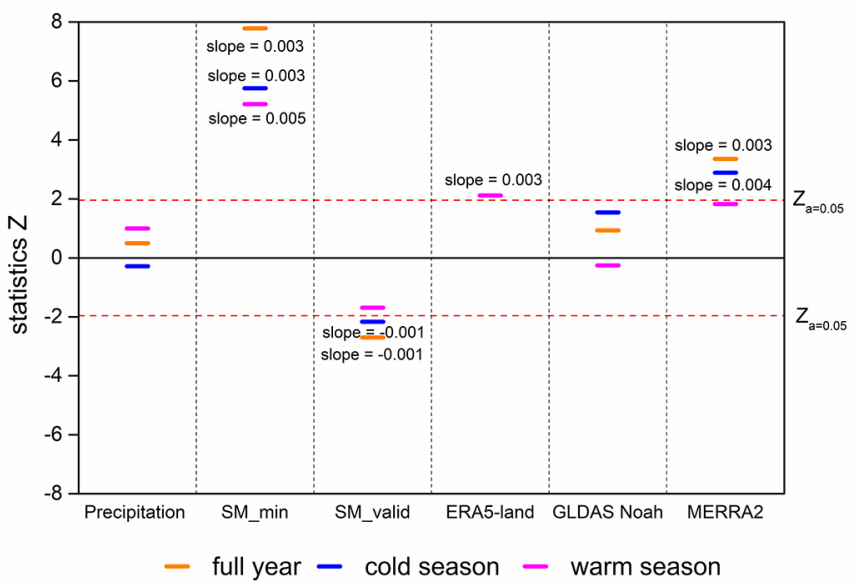

Figure 9. Mann-Kendall trend test and Sen's slope estimate for precipitation, $\mathrm{SM}_{\mathrm{AA} \text {-min }}$, $\mathrm{SM}_{\mathrm{AA} \text {-valid }}$, and model-based SM derived from the ERA5-Land, GLDAS Noah, and MERRA2 for a 10-year period for the (a) Maqu and (b) Shiquanhe networks.

a monotonous trend if the absolute value of the $Z$ metric were greater than a critical value, i.e. $Z_{0.05}=1.96$ in this study. The results show that no significant trend is found for both precipitation and $\mathrm{SM}_{\mathrm{AA}-\mathrm{min}}$ time series, while the $\mathrm{SM}_{\mathrm{AA} \text {-valid }}$ shows a drying trend with a Sen's slope of -0.008 for warm seasons. The drying trend of the $\mathrm{SM}_{\mathrm{AA} \text {-valid }}$ is caused by the change of available SM monitoring sites (see Table A2). Specifically, several monitoring sites (e.g. NST11-NST15) located in the wetter area were damaged from 2013 onwards, and four new monitoring sites (i.e. NST21-NST25) were in- stalled in the drier area in 2015 (see Table 2), which affects the trend of the $\mathrm{SM}_{\mathrm{AA} \text {-valid. }}$

Figure $8 \mathrm{~b}$ shows the time series of the $\mathrm{SM}_{\mathrm{AA}-\mathrm{min}}$ and $\mathrm{SM}_{\mathrm{AA} \text {-valid }}$ along with the daily precipitation data for the Shiquanhe network during the period between August 2010 and August 2019. The two time series of the SM display a similar seasonality to that found for the Maqu network (see subplot of Fig. 8b). However, obvious deviations can be noticed for the inter-annual variations, and the $\mathrm{SM}_{\mathrm{AA}}$-valid tends to produce larger values before 2014 but smaller values thereafter. 
The Mann-Kendall trend test and Sen's slope estimate for the

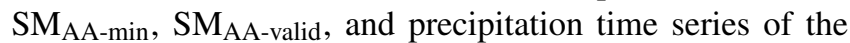
Shiquanhe network area are shown in Fig. 9b. The SMAA-min demonstrates a wetting trend with a Sen's slope of 0.003 , while an opposite drying trend is found for the $\mathrm{SM}_{\mathrm{AA} \text {-valid }}$ due to a change in the number of available SM monitoring sites (see Table A4) similar to the results from the Maqu network. Specifically, several monitoring sites (e.g. SQ11 and SQ12) located in the wetter area were damaged around 2014, and five new monitoring sites (i.e. SQ17-21) were installed in the drier area in 2016 (see Table 3).

In summary, the $\mathrm{SM}_{\mathrm{AA} \text {-valid }}$ is likely affected by the change of available SM monitoring sites over time that leads to an inconsistent trend with the $\mathrm{SM}_{\mathrm{AA}-\mathrm{min}}$. This indicates that the $\mathrm{SM}_{\mathrm{AA}-\mathrm{min}}$ is superior to the $\mathrm{SM}_{\mathrm{AA} \text {-valid }}$ for the production of the long-term consistent upscaled SM time series.

\subsection{Application of the long-term upscaled soil moisture to validate the model-based products}

In this section, the long-term upscaled SM time series (i.e. $\mathrm{SM}_{\mathrm{AA} \text {-min }}$ ) produced for the two networks are applied to validate the reliability of three model-based SM products - i.e. ERA5-Land, MERRA2, and GLDAS Noah - to demonstrate the uniqueness of this dataset for validating existing reanalysis datasets for a long-term period ( $\sim 10$ years). Since the ERA5-Land product provides only total volumetric soil water content, the period when the soil is subject to freezing and thawing (i.e. November-April) is excluded for this evaluation.

Figure 10a shows the time series of $\mathrm{SM}_{\mathrm{AA}-\mathrm{min}}$ and daily average SM data derived from the three products for the Maqu network during the period between May 2009 and May 2019. The error statistics, i.e. bias and RMSE, computed between the three products and the $\mathrm{SM}_{\mathrm{AA}-\mathrm{min}}$ for both warm (May-October) and cold seasons (November-April) are given in Table 5. Although the three products generally capture the seasonal variations of the $\mathrm{SM}_{\mathrm{AA} \text {-min }}$, the magnitude of the temporal SM variability is underestimated. Both GLDAS Noah and MERRA2 products underestimate the SM measurements during the warm season, leading to biases of about -0.112 and $-0.113 \mathrm{~m}^{3} \mathrm{~m}^{-3}$, respectively. This may be due to the fact that the land surface models (LSMs) adopted for producing these products do not consider the impact of vertical soil heterogeneity caused by organic matter content, which is widely present in the soil Tibetan surface (Chen et al., 2013; Zheng et al., 2015a). In addition, the MERRA2 product overestimates the SM measurements during the cold season with a bias of about $0.006 \mathrm{~m}^{3} \mathrm{~m}^{-3}$. The ERA5-Land product is able to capture the magnitude of $\mathrm{SM}_{\mathrm{AA}-\mathrm{min}} \mathrm{dy}-$ namics in the warm season but has a larger volatility and yields a RMSE of about $0.067 \mathrm{~m}^{3} \mathrm{~m}^{-3}$. The trend analysis for the three model-based SM products is shown in Fig. 9a as well. All three products do not show a significant trend in warm seasons like the $\mathrm{SM}_{\mathrm{AA}-\mathrm{min}}$, while the GLDAS Noah (a) Maqu

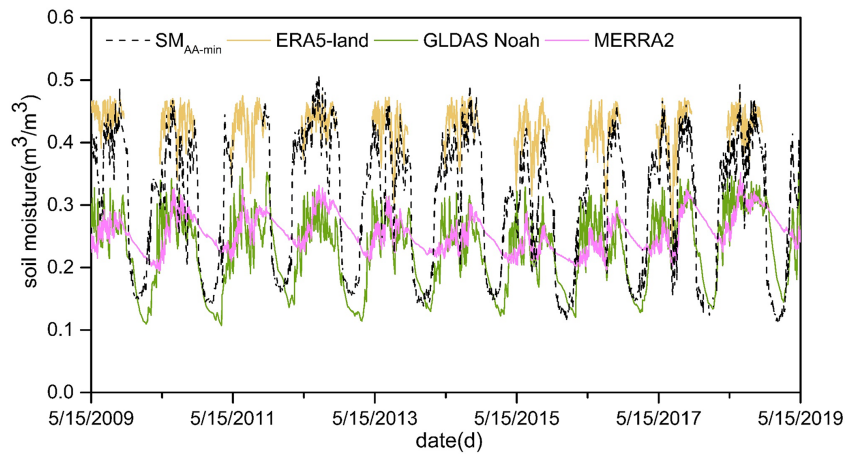

(b) Shiquanhe

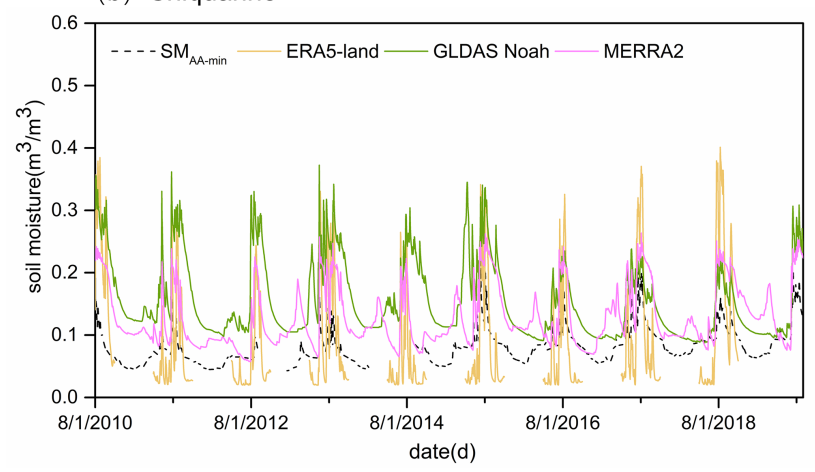

Figure 10. A 10-year time series of model-based SM derived from the ERA5-Land, MERRA2, and GLDAS Noah products and the upscaled SM ( $\mathrm{SM}_{\mathrm{AA}-\mathrm{min}}$ ) for the (a) Maqu and (b) Shiquanhe networks. The date format is month/day/year.

and MERRA2 products show a wetting trend in cold seasons that is in disagreement with the $\mathrm{SM}_{\mathrm{AA}-\mathrm{min}}$ trend.

Figure $10 \mathrm{~b}$ shows the time series of $\mathrm{SM}_{\mathrm{AA}-\mathrm{min}}$ and daily SM data derived from the three products for the Shiquanhe network area during the period between August 2010 and August 2019, and the corresponding error statistics are given in Table 5 as well. Although the three products generally capture the seasonal variations of the $\mathrm{SM}_{\mathrm{AA}-\mathrm{min}}$, both GLDAS Noah and MERRA2 products overestimate the $\mathrm{SM}_{\mathrm{AA}-\mathrm{min}}$ during the entire study period, leading to positive biases, and a positive bias (about $0.002 \mathrm{~m}^{3} \mathrm{~m}^{-3}$ ) is also found in the ERA5-Land product for the warm season. The trend analyses for the three SM products are also shown in Fig. 9b. Both the ERA5-Land and MERRA2 products are able to reproduce the wetting trend found for the $\mathrm{SM}_{\mathrm{AA}-\mathrm{min}}$, while the GLDAS Noah product is not able to capture the trend.

In summary, the currently model-based SM products do not provide a reliable representation of the trend and the dynamics of measured SM in the long term ( $\sim 10$ years $)$ in the grassland and desert ecosystems that dominate the Tibetan landscape. 
Table 5. Error statistics computed between the $\mathrm{SM}_{\mathrm{AA}-\mathrm{min}}$ and the three model-based SM products for the Maqu and Shiquanhe networks.

\begin{tabular}{|c|c|c|c|c|}
\hline & $\operatorname{bias}\left(\mathrm{m}^{3} \mathrm{~m}^{-3}\right)$ & $\operatorname{RMSE}\left(\mathrm{m}^{3} \mathrm{~m}^{-3}\right)$ & $\operatorname{bias}\left(m^{3} m^{-3}\right)$ & $\operatorname{RMSE}\left(\mathrm{m}^{3} \mathrm{~m}^{-3}\right)$ \\
\hline & \multicolumn{2}{|c|}{ warm season } & \multicolumn{2}{|c|}{ cold season } \\
\hline \multicolumn{5}{|l|}{ Maqu } \\
\hline ERA5-Land & 0.050 & 0.067 & - & - \\
\hline GLDAS Noah & -0.112 & 0.125 & -0.049 & 0.088 \\
\hline MERRA2 & -0.113 & 0.124 & 0.006 & 0.097 \\
\hline \multicolumn{5}{|l|}{ Shiquanhe } \\
\hline ERA5-Land & 0.002 & 0.079 & - & - \\
\hline GLDAS Noah & 0.010 & 0.116 & 0.052 & 0.058 \\
\hline MERRA2 & 0.054 & 0.069 & 0.049 & 0.053 \\
\hline
\end{tabular}

\section{Discussion}

As shown in previous sections, the number of available SM monitoring sites in the Tibet-Obs generally changes with time. For instance, several monitoring sites of the Maqu network located in the wetter area have been damaged since 2013, and four new monitoring sites were installed in the drier area in 2015, which affects the trend of SM time series (i.e. $\mathrm{SM}_{\mathrm{AA} \text {-valid }}$ shown in Sect. 4.2). On the other hand, the 10-year upscaled SM data (i.e. $\mathrm{SM}_{\mathrm{AA}-\mathrm{min}}$ ) produced in this study utilizing three and four monitoring sites with longterm continuous measurements would yield RMSEs of about 0.022 and $0.011 \mathrm{~m}^{3} \mathrm{~m}^{-3}$ for the Maqu and Shiquanhe networks, respectively (see Sect. 4.1). Therefore, to provide a higher-quality continuous SM time series for the future, it is necessary to find an appropriate strategy to maintain the monitoring sites of Tibet-Obs. This section discusses the possible strategies with the Maqu and Shiquanhe networks as examples.

At first, a sensitivity analysis is conducted to quantify the impact of the number of monitoring sites on the regional SM estimate. The SM time series described in Sect. 4.1 (i.e. November 2009-October 2010 for the Maqu network and August 2018-July 2019 for the Shiquanhe network) is used to test the sensitivity, and there are in total 17 and 12 available monitoring sites for the Maqu and Shiquanhe networks, respectively. Taking the Maqu network as an example, we randomly pick different numbers of sites from 1 to 16 of the 17 sites to make up different combinations and then compute the RMSEs of the averaged SM obtained with these combinations (Famiglietti et al., 2008; Zhao et al., 2013). These RMSEs are further grouped into nine levels ranging from 0.004 to $0.02 \mathrm{~m}^{3} \mathrm{~m}^{-3}$, and the percentage of the combinations falling into each level is summarized in Table 6. In general, the percentage increases with an increasing number of monitoring sites at any RMSE level. It can be noted that more than $50 \%$ of combinations are able to comply with the RMSE requirement of $0.004 \mathrm{~m}^{3} \mathrm{~m}^{-3}$ if the number of available monitoring sites is 16 and 11 in the Maqu and Shiquanhe networks, respectively. If the number of available monitoring sites is more than 13 and 6 in the Maqu and Shiquanhe networks, respectively, then about $60 \%$ of combinations with 13 sites (6 sites) are able to comply with the RMSE requirement of $0.01 \mathrm{~m}^{3} \mathrm{~m}^{-3}$. For a RMSE of $0.02 \mathrm{~m}^{3} \mathrm{~m}^{-3}$, more than $50 \%$ of combinations comply with this requirement if the number of available monitoring sites is more than 7 and 3 for the two networks, respectively. In summary, the number of monitoring sites required to maintain current networks depends on the defined RMSE requirement.

As shown in Sect. 4.1, the usage of a minimum number of sites (i.e. three for Maqu and four for Shiquanhe) with about 10 -year continuous measurements yields RMSEs of 0.022 and $0.011 \mathrm{~m}^{3} \mathrm{~m}^{-3}$ for the Maqu and Shiquanhe networks, respectively. Since there are still 12 monitoring sites providing SM measurements for both networks until 2019 (see Tables 2 and 3), it is possible to decrease the RMSEs when the selected permanent monitoring sites are appropriately determined. For the Shiquanhe network, the optimal strategy is to keep the current 12 monitoring sites, which is exactly the combination used in Sect. 4.1. For the Maqu network, it can be found that about $3.52 \%$ of combinations with 12 sites could yield the minimum RMSE of $0.006 \mathrm{~m}^{3} \mathrm{~m}^{-3}$ (see Table 6). In order to find the optimal combination with 12 sites for the Maqu network, all the possible combinations (i.e. 6188 combinations) are ranked by RMSE values from the smallest to largest, and Table 7 lists the examples of ranking 1 st-5th and 95th-100th. It can be noted that the 100th combination contains the largest number of currently available monitoring sites (i.e. seven sites, including CST03, CST05, NST01, NST03, NST05, NST06, and NST10) with a RMSE of less than $0.006 \mathrm{~m}^{3} \mathrm{~m}^{-3}$. Therefore, the 100th combination of 12 monitoring sites (as shown in Table 7) is suggested for the Maqu network.

In summary, it is suggested to maintain the current 12 monitoring sites for the Shiquanhe network, while for the Maqu network it is suggested to restore five old monitoring sites, i.e. CST02, NST11, NST13, NST14, and NST15. 
Table 6. Percentages of the site combinations that fall into an accuracy requirement in terms of RMSE.

\begin{tabular}{|c|c|c|c|c|c|c|c|c|c|}
\hline RMSE & 0.004 & 0.006 & 0.008 & 0.010 & 0.012 & 0.014 & 0.016 & 0.018 & 0.020 \\
\hline \multicolumn{10}{|c|}{ Maqu network } \\
\hline \multicolumn{10}{|l|}{$n=1(\%)$} \\
\hline$n=2(\%)$ & & & & & & & & 0.74 & 3.68 \\
\hline$n=3(\%)$ & & & & & & 0.44 & 1.32 & 3.97 & 7.79 \\
\hline$n=4(\%)$ & & & & & 0.21 & 1.05 & 3.74 & 9.16 & 16.93 \\
\hline$n=5(\%)$ & & & & 0.03 & 0.58 & 3.10 & 9.31 & 18.23 & 28.18 \\
\hline$n=6(\%)$ & & & & 0.09 & 1.87 & 8.27 & 19.18 & 31.22 & 42.36 \\
\hline$n=7(\%)$ & & & & 0.69 & 6.21 & 18.11 & 31.91 & 43.98 & 54.32 \\
\hline$n=8(\%)$ & & & 0.08 & 3.29 & 14.97 & 30.32 & 43.97 & 55.36 & 64.79 \\
\hline$n=9(\%)$ & & & 0.84 & 9.58 & 26.27 & 42.42 & 55.47 & 65.94 & 74.16 \\
\hline$n=10(\%)$ & & 0.01 & 3.91 & 19.74 & 38.94 & 54.41 & 66.13 & 75.21 & 82.23 \\
\hline$n=11(\%)$ & & 0.53 & 11.10 & 32.92 & 51.7 & 65.66 & 75.9 & 83.32 & 88.87 \\
\hline$n=12(\%)$ & & 3.52 & 23.95 & 47.3 & 64.03 & 75.87 & 84.45 & 90.14 & 94.30 \\
\hline$n=13(\%)$ & 0.29 & 13.82 & 39.87 & 61.81 & 75.67 & 85.38 & 91.55 & 95.38 & 97.77 \\
\hline$n=14(\%)$ & 3.68 & 32.35 & 57.79 & 74.85 & 86.47 & 92.79 & 96.91 & 98.82 & 99.41 \\
\hline$n=15(\%)$ & 21.32 & 56.62 & 75.00 & 88.97 & 95.59 & 98.53 & 99.26 & 100.00 & 100.00 \\
\hline$n=16(\%)$ & 52.94 & 82.35 & 94.12 & 94.12 & 100.00 & 100.00 & 100.00 & 100.00 & 100.00 \\
\hline \multicolumn{10}{|c|}{ Shiquanhe network } \\
\hline$n=1(\%)$ & & & & & & & 8.33 & 16.67 & 25.00 \\
\hline$n=2(\%)$ & & 1.52 & 1.52 & 4.55 & 13.64 & 30.30 & 37.88 & 42.42 & 48.48 \\
\hline$n=3(\%)$ & & 6.82 & 21.36 & 25.45 & 33.18 & 42.73 & 53.18 & 59.55 & 65.00 \\
\hline$n=4(\%)$ & 1.62 & 11.31 & 29.7 & 41.41 & 51.11 & 57.37 & 63.23 & 70.51 & 77.58 \\
\hline$n=5(\%)$ & 3.66 & 23.11 & 36.87 & 49.12 & 60.23 & 68.18 & 76.14 & 82.32 & 88.26 \\
\hline$n=6(\%)$ & 11.36 & 30.95 & 44.37 & 59.85 & 70.24 & 79.11 & 85.28 & 90.15 & 93.29 \\
\hline$n=7(\%)$ & 20.20 & 39.77 & 56.06 & 68.31 & 77.90 & 86.87 & 93.43 & 96.84 & 98.48 \\
\hline$n=8(\%)$ & 29.29 & 50.51 & 62.63 & 77.58 & 89.09 & 96.57 & 97.98 & 98.99 & 99.60 \\
\hline$n=9(\%)$ & 33.64 & 59.55 & 82.73 & 91.36 & 96.36 & 98.18 & 99.55 & 99.55 & 100.00 \\
\hline$n=10(\%)$ & 48.48 & 78.79 & 92.42 & 96.97 & 96.97 & 100.00 & 100.00 & 100.00 & 100.00 \\
\hline$n=11(\%)$ & 83.33 & 91.67 & 100.00 & 100.00 & 100.00 & 100.00 & 100.00 & 100.00 & 100.00 \\
\hline
\end{tabular}

Table 7. The combinations of monitoring sites ranked by RMSE values of average SM in the Maqu network.

\begin{tabular}{|c|c|c|c|c|c|c|c|c|c|c|c|c|c|}
\hline Rank & Site 1 & Site2 & Site3 & Site4 & Site5 & Site6 & Site7 & Site8 & Site9 & Site10 & Site11 & Site12 & RMSE \\
\hline 1 & CST01 & CST02 & NST02 & NST03 & NST04 & NST05 & NST06 & NST07 & NST10 & NST13 & NST14 & NST15 & 0.00402 \\
\hline 2 & CST01 & CST02 & CST04 & NST01 & NST02 & NST03 & NST04 & NST05 & NST06 & NST07 & NST13 & NST15 & 0.00417 \\
\hline 3 & СST02 & NST01 & NST02 & NST03 & NST04 & NST05 & NST06 & NST07 & NST10 & NST13 & NST14 & NST15 & 0.00450 \\
\hline 4 & CST01 & CST02 & NST01 & NST02 & NST03 & NST04 & NST05 & NST06 & NST07 & NST13 & NST14 & NST15 & 0.00450 \\
\hline 5 & CST01 & CST02 & CST03 & NST02 & NST03 & NST04 & NST05 & NST06 & NST07 & NST10 & NST14 & NST15 & 0.00451 \\
\hline 96 & CST01 & CST02 & CST03 & CST04 & CST05 & NST03 & NST06 & NST10 & NST11 & NST13 & NST14 & NST15 & 0.00555 \\
\hline 97 & CST01 & CST02 & CST03 & NST01 & NST02 & NST04 & NST05 & NST06 & NST11 & NST13 & NST14 & NST15 & 0.00555 \\
\hline 98 & CST01 & CST02 & CST03 & CST04 & CST05 & NST01 & NST02 & NST05 & NST06 & NST10 & NST11 & NST15 & 0.00556 \\
\hline 99 & CST03 & NST02 & NST03 & NST04 & NST05 & NST06 & NST07 & NST10 & NST11 & NST13 & NST14 & NST15 & 0.00557 \\
\hline 100 & CST02 & CST03 & CST05 & NST01 & NST03 & NST05 & NST06 & NST10 & NST11 & NST13 & NST14 & NST15 & 0.00557 \\
\hline
\end{tabular}

\section{Data availability}

The 10-year (2009-2019) surface SM dataset is freely available from the 4TU.ResearchData repository at https://doi.org/10.4121/12763700.v7 (Zhang et al., 2020). The original in situ SM data, the upscaled SM data, and the supplementary data are stored in .xlsx files. A user guide document is given to introduce the content of the dataset, the status of the Tibet-Obs, and the online dataset utilized in the study. 


\section{Conclusions}

In this paper, we report on the status of the Tibet-Obs and present the long-term in situ SM and spatially upscaled SM dataset for the period 2009-2019. In general, the number of available SM monitoring sites decreased over time due to damage to sensors. Until 2019, there are only three and four sites that provide an approximately 10-year consistent SM time series for the Maqu and Shiquanhe networks, respectively. Comparisons between four upscaling methods - i.e. arithmetic averaging (AA), Voronoi diagram (VD), time stability (TS), and apparent thermal inertia (ATI) - show that the AA method with input of the maximum number of available SM monitoring sites (AA-max) can be used to represent the actual areal SM conditions $\left(\mathbf{S M}_{\text {truth }}\right)$. The arithmetic average of the three and four monitoring sites with longterm continuous measurements (AA-min) is found to be most suitable to produce the upscaled SM dataset for the period 2009-2019, which yields RMSEs of 0.022 and $0.011 \mathrm{~m}^{3} \mathrm{~m}^{-3}$ for the Maqu and Shiquanhe networks in comparison to the $\mathrm{SM}_{\text {truth}}$.

Trend analysis of the approximately 10-year upscaled SM time series produced by the AA-min ( $\left.\mathrm{SM}_{\mathrm{AA}-\mathrm{min}}\right)$ shows that the Shiquanhe network in the western part of the TP gets wet, while no significant trend is found for the Maqu network in the east. The usage of all the available monitoring sites each year leads to inconsistent time series of SM that cannot capture the trend of $\mathrm{SM}_{\mathrm{AA}-\mathrm{min}}$ reliably. Comparisons between the $\mathrm{SM}_{\mathrm{AA}-\mathrm{min}}$ and the model-based SM products from the ERA5-Land, GLDAS Noah, and MERRA2 further demonstrate that current model-based SM products still show deficiencies in representing the trend and the dynamics of the SM measured on the TP. Moreover, strategies for maintaining the Tibet-Obs are provided, and it is suggested to maintain the 12 current operational sites for the Shiquanhe network, while for the Maqu network it is suggested to restore five old sites.

The 10-year (2009-2019) surface SM dataset presented in this paper includes the $15 \mathrm{~min}$ in situ measurements taken at a depth of $5 \mathrm{~cm}$ collected from three regional-scale networks (i.e. Maqu, Naqu, and Ngari including Ali and Shiquanhe) of the Tibet-Obs and the spatially upscaled SM datasets produced by the AA-min for the Maqu and Shiquanhe networks. This dataset is valuable for calibrating/validating long-term satellite- and model-based SM products, evaluation of SM upscaling methods, development of data fusion methods, and quantifying the coupling of SM with precipitation at a 10year scale. 
Appendix A: Basic information of the Tibet-Obs

Table A1. Site information of the Maqu network (site name, elevation, topography (TPG), land cover (LC), soil texture at 5-15 cm depth (STX), soil bulk density at $5 \mathrm{~cm}$ depth (BD), soil organic matter content at 5-15 cm depth (OMC), not available (NA); BD and OMC values are measured in the laboratory).

\begin{tabular}{lrlllrr}
\hline Site name & Elevation $(\mathrm{m})$ & TPG & LC & STX & $\mathrm{BD}\left(\mathrm{kg} \mathrm{m}^{-3}\right)$ & ${\mathrm{OMC}\left(\mathrm{g} \mathrm{kg}^{-1}\right)}^{-}$ \\
\hline CST01 & 3431 & River valley & Grass & NA & NA & NA \\
CST02 & 3449 & River valley & Grass & NA & NA & NA \\
CST03 & 3507 & Hill valley & Grass & NA & NA & NA \\
CST04 & 3504 & Hill valley & Grass & NA & NA & NA \\
CST05 & 3542 & Hill valley & Grass & NA & 0.96 & 18 \\
NST01 & 3431 & River valley & Grass & Silt loam & 0.81 & 18 \\
NST02 & 3434 & River valley & Grass & Silt loam & 0.63 & 49 \\
NST03 & 3513 & Hill slope & Grass & Silt loam & 0.26 & 229 \\
NST04 & 3448 & River valley & Wetland & Silt loam & 0.75 & 22 \\
NST05 & 3476 & Hill slope & Grass & Silt loam & 0.81 & 23 \\
NST06 & 3428 & River valley & Grass & Silt loam & 0.58 & 23 \\
NST07 & 3430 & River valley & Grass & Silt loam & 1.06 & 34 \\
NST08 & 3473 & Valley & Grass & Silt loam & 0.91 & 17 \\
NST09 & 3434 & River valley & Grass & Sandy loam & 1.05 & 24 \\
NST10 & 3512 & Hill slope & Grass & Loam-silt loam & 0.24 & 136 \\
NST11 & 3442 & River valley & Wetland & Organic soil & 1.02 & 39 \\
NST12 & 3441 & River valley & Grass & Silt loam & 0.67 & 29 \\
NST13 & 3519 & Valley & Grass & Silt loam & 0.68 & 30 \\
NST14 & 3432 & River valley & Grass & Silt loam & 0.78 & 56 \\
NST15 & 3752 & Hill slope & Grass & Silt loam & NA & NA \\
NST21 & 3428 & River valley & Grass & Silt loam & NA & NA \\
NST22 & 3440 & River valley & Grass & Silt loam & NA & NA \\
NST24 & 3446 & River valley & Grass & Silt loam & NA & NA \\
NST25 & 3600 & Hill slope & Grass & Silt loam & NA & NA \\
NST31 & 3490 & NA & NA & NA & NA & NA \\
NST32 & 3490 & Hill valley & Grass & NA & & \\
\hline & & & & & & \\
& & & & & & \\
\hline
\end{tabular}


Table A2. Soil moisture with temporal persistence for the Maqu network. Cells with a hyphen represent that no data are missing; cells with "M" indicate data are missing with little influence.

\begin{tabular}{|c|c|c|c|c|c|c|c|c|c|}
\hline Time & $\begin{array}{l}\text { Nov 2009- } \\
\text { Nov } 2010\end{array}$ & $\begin{array}{l}\text { Nov 2010- } \\
\text { Nov } 2011\end{array}$ & $\begin{array}{l}\text { Nov 2011- } \\
\text { Nov } 2012\end{array}$ & $\begin{array}{l}\text { Nov 2012- } \\
\text { Nov } 2013\end{array}$ & $\begin{array}{l}\text { Nov 2013- } \\
\text { Nov } 2014\end{array}$ & $\begin{array}{l}\text { Nov 2014- } \\
\text { Nov } 2015\end{array}$ & $\begin{array}{l}\text { Nov 2015- } \\
\text { Nov } 2016\end{array}$ & $\begin{array}{l}\text { Nov 2016- } \\
\text { Nov } 2017\end{array}$ & $\begin{array}{l}\text { Nov 2017- } \\
\text { Nov } 2018\end{array}$ \\
\hline CST05 & - & - & - & - & - & - & - & - & - \\
\hline NST01 & - & - & - & - & - & - & M & - & - \\
\hline NST03 & - & M & - & - & - & - & M & - & - \\
\hline NST06 & - & M & - & - & - & - & - & & \\
\hline NST07 & - & - & - & - & - & - & & & \\
\hline NST13 & - & - & - & - & - & - & & & \\
\hline NST01 & - & - & - & - & & & & & \\
\hline NST14 & - & - & - & - & & & & & \\
\hline CST03 & - & - & - & & & & & & \\
\hline NST05 & - & - & - & & & & & & \\
\hline CST01 & - & - & & & & & & & \\
\hline CST04 & - & - & & & & & & & \\
\hline NST02 & - & - & & & & & & & \\
\hline NST04 & - & - & & & & & & & \\
\hline CST02 & - & & & & & & & & \\
\hline NST10 & - & & & & & & & & \\
\hline NST15 & - & & & & & & & & \\
\hline
\end{tabular}

Table A3. Same as Table A1 but for the Ngari network (BD and OMC data are not available).

\begin{tabular}{lllll}
\hline Site name & Elevation (m) & TPG & LC & STX \\
\hline Shiquanhe network & & & & \\
\hline SQ01 & 4306 & Flat & Desert & Loamy sand \\
SQ02 & 4304 & Gentle slope & Desert & Sand \\
SQ03 & 4278 & Gentle slope & Desert (with sparse bushes) & Sand \\
SQ04 & 4269 & Edge of a wetland & Sparse grass & Loamy sand \\
SQ05 & 4261 & Edge of a marsh & Sparse grass & Sand \\
SQ06 & 4257 & Flat & Sparse grass & Loamy Sand \\
SQ07 & 4280 & Flat & Desert (with sparse bushes) & Sand \\
SQ08 & 4306 & Flat & Desert & Sand \\
SQ09 & 4275 & Flat & Desert/river bed & Sand \\
SQ10 & 4275 & Flat & Grassland & Fine sand with some thick roots \\
SQ11 & 4274 & Flat & Grassland with bushes & Loamy sand \\
SQ12 & 4264 & Flat & Edge of riverbed & Sandy loam \\
SQ13 & 4292 & Flat & Valley bottom & Sand \\
SQ14 & 4368 & Slope & Desert & Sandy loam \\
SQ16 & 4288 & Flat & Desert/river bed & Loam \\
SQ17 & 4563 & NA & NA & NA \\
SQ18 & 4634 & NA & NA & NA \\
SQ19 & 4647 & NA & NA & NA \\
SQ20 & 4695 & NA & NA & NA \\
SQ21 & 4606 & NA & NA & NA \\
\hline Ali network & & & & \\
\hline Ali & 4288 & Flat & Grass & Loamy sand \\
Ali01 & 4262 & Flat & Sparse grass & Sand \\
Ali02 & 4266 & Flat & Sparse grass & Sand \\
Ali03 & 4261 & Edge of a wetland & Grass & Sand \\
\hline & & & &
\end{tabular}


Table A4. Same as Table A2 but for the Shiquanhe network.

\begin{tabular}{|c|c|c|c|c|c|c|c|c|c|}
\hline Time & $\begin{array}{l}\text { Aug 2010- } \\
\text { Aug 2011 }\end{array}$ & $\begin{array}{l}\text { Aug 2011- } \\
\text { Aug } 2012\end{array}$ & $\begin{array}{l}\text { Aug 2012- } \\
\text { Aug 2013 }\end{array}$ & $\begin{array}{l}\text { Aug 2013- } \\
\text { Aug 2014 }\end{array}$ & $\begin{array}{l}\text { Aug 2014- } \\
\text { Aug 2015 }\end{array}$ & $\begin{array}{l}\text { Aug 2015- } \\
\text { Aug 2016 }\end{array}$ & $\begin{array}{l}\text { Aug 2016- } \\
\text { Aug } 2017\end{array}$ & $\begin{array}{l}\text { Aug 2017- } \\
\text { Aug } 2018\end{array}$ & $\begin{array}{l}\text { Aug 2018- } \\
\text { Aug } 2019\end{array}$ \\
\hline SQ02 & - & - & - & M & - & - & - & - & - \\
\hline SQ03 & - & - & - & - & - & - & - & - & - \\
\hline SQ06 & - & - & $\mathrm{M}$ & $\mathrm{M}$ & - & - & - & - & - \\
\hline SQ14 & - & - & - & - & - & - & - & - & - \\
\hline SQ08 & & & & - & - & - & - & - & - \\
\hline SQ07 & & & & & - & - & - & - & - \\
\hline SQ17 & & & & & & & - & - & - \\
\hline SQ19 & & & & & & & - & - & - \\
\hline SQ20 & & & & & & & - & - & - \\
\hline SQ21 & & & & & & & - & - & - \\
\hline SQ10 & & & & & & & & - & - \\
\hline SQ11 & & & & & & & & & - \\
\hline
\end{tabular}

Table A5. Same as Table A1 but for the Naqu network (BD and OMC data are not available).

\begin{tabular}{lrlll}
\hline Site name & Elevation $(\mathrm{m})$ & TPG & LC & STX \\
\hline Naqu & 4509 & Plain & Grassland & Loamy sand \\
East & 4527 & Flat hill top & Grassland & Loamy sand \\
West & 4506 & Plain & Grassland & Loamy sand \\
North & 4507 & Slope on riverbank & Grassland & Loamy sand \\
South & 4510 & Slope of wetland & Wetland & Loamy sand \\
Kema & 4465 & River valley & Grass & Silt loam \\
MS & 4583 & NA & NA & NA \\
NQ01 & 4517 & NA & NA & NA \\
NQ02 & 4552 & NA & NA & NA \\
NQ03 & 4638 & NA & NA & NA \\
NQ04 & 4632 & NA & NA & NA \\
\hline
\end{tabular}




\section{Appendix B: Spatial upscaling methods}

\section{B1 Arithmetic averaging}

The arithmetic averaging method assigns an equal weight coefficient to each SM monitoring site of the network, which can be formulated as

$\overline{\boldsymbol{\theta}}_{t}^{\mathrm{ups}}=\frac{1}{N} \sum_{i=1}^{N} \boldsymbol{\theta}_{t, i}^{\mathrm{obs}}$,

where $i$ represents the $i$ th SM monitoring site.

\section{B2 Voronoi diagram}

The Voronoi diagram method divides the network area into several parts according to the distances between each SM monitoring site. This approach determines the weight of each site $\left(w_{i}(-)\right)$ based on the geographic distribution of all the SM monitoring sites within the network area, which can be formulated as

$\overline{\boldsymbol{\theta}}_{t}^{\mathrm{ups}}=\frac{\sum_{i=1}^{N} w_{i} \boldsymbol{\theta}_{t, i}^{\mathrm{obs}}}{\sum_{i=1}^{N} w_{i}}$.

\section{B3 Time stability}

The time stability method is based on the assumption that the spatial SM pattern over time tends to be consistent (Vachaud et al., 1985), and the most stable site can be regarded as the representative site of the network. For each SM monitoring site $i$ within the time window ( $M$ days in total), the mean relative difference $\mathrm{MRD}_{i}(-)$ and standard deviation of the relative difference $\sigma\left(\mathrm{RD}_{i}\right)(-)$ are estimated as

$\sigma\left(\mathrm{RD}_{i}\right)=\sqrt{\frac{1}{M-1} \sum_{t=1}^{M}\left(\mathrm{RD}_{t, i}-\mathrm{MRD}_{i}\right)^{2}}$,

$\mathrm{MRD}_{i}=\frac{1}{M} \sum_{t=1}^{M} \frac{\boldsymbol{\theta}_{t, i}^{\mathrm{obs}}-\overline{\boldsymbol{\theta}_{t}^{\mathrm{obs}}}}{\overline{\boldsymbol{\theta}_{t}^{\mathrm{obs}}}}$,

$\mathrm{RD}_{t, i}=\frac{\boldsymbol{\theta}_{t, i}^{\mathrm{obs}}-\overline{\boldsymbol{\theta}_{t}^{\mathrm{obs}}}}{\overline{\boldsymbol{\theta}_{t}^{\mathrm{obs}}}}$,

where $\theta_{t, i}^{\mathrm{obs}}\left(\mathrm{m}^{3} \mathrm{~m}^{-3}\right)$ represents the SM measured on the $t$ th day at the $i$ th monitoring site, $\overline{\boldsymbol{\theta}_{t}^{\text {obs }}}\left(\mathrm{m}^{3} \mathrm{~m}^{-3}\right)$ represents the mean SM measured at all available monitoring sites on the $t$ th day. $\mathrm{MRD}_{i}$ quantifies the bias of each SM monitoring site to identify a particular location as wetter or drier than the regional mean, and $\sigma\left(\mathrm{RD}_{i}\right)$ characterizes the precision of the SM measurement. Jacobs et al. (2004) combined the above two statistical metrics as a comprehensive evaluation criterion $\left(\mathrm{CEC}_{i}(-)\right)$ :

$\mathrm{CEC}_{i}=\sqrt{\left(\mathrm{MRD}_{i}\right)^{2}+\sigma\left(\mathrm{RD}_{i}\right)^{2}}$.

The most stable site is identified by the lowest $\mathrm{CEC}_{i}$ value.

\section{B4 Apparent thermal inertia}

The apparent thermal inertia (ATI) method is based on the close relationship between apparent thermal inertia $\left(\tau\left(\mathrm{K}^{-1}\right)\right)$ and $\operatorname{SM}\left(\boldsymbol{\theta}\left(\mathrm{m}^{3} \mathrm{~m}^{-3}\right)\right)$ (Van doninck et al., 2011; Veroustraete et al., 2012). If the true areal SM $\left(\overline{\boldsymbol{\theta}}_{t}^{\mathrm{tru}}\left(\mathrm{m}^{3} \mathrm{~m}^{-3}\right)\right)$ is available, then the weight vector $\boldsymbol{\beta}$ can be derived by the ordinary leastsquares (OLS) method, which minimizes the cost function $J$ as

$J=\sum_{t=1}^{M}\left(\boldsymbol{\theta}_{t}^{\mathrm{tru}}-\boldsymbol{\beta}^{T} \boldsymbol{\theta}_{t}^{\mathrm{obs}}\right)^{2}$.

However, the $\boldsymbol{\theta}_{t}^{\text {tru }}\left(\mathrm{m}^{3} \mathrm{~m}^{-3}\right)$ is usually not available in practice, and the representative SM $\left(\overline{\boldsymbol{\theta}}_{t}^{\mathrm{rep}}\left(\mathrm{m}^{3} \mathrm{~m}^{-3}\right)\right)$ is thus introduced, which contains random noise but with no bias. Since the OLS method may result in overfitting with usage of the $\overline{\boldsymbol{\theta}}_{t}^{\text {rep }}$, a regularization term is introduced, and Eq. (B7) can be re-formulated as (Tarantola, 2005)

$$
\begin{aligned}
J= & \sum_{t=1}^{M}\left(\overline{\boldsymbol{\theta}}_{t}^{\mathrm{rep}}-\boldsymbol{\beta}^{T} \boldsymbol{\theta}_{t}^{\mathrm{obs}}\right) \sigma^{-2} \\
& \cdot\left(\overline{\boldsymbol{\theta}}_{t}^{\mathrm{rep}}-\boldsymbol{\beta}^{T} \boldsymbol{\theta}_{t}^{\mathrm{obs}}\right)+R \boldsymbol{\beta}^{T} \boldsymbol{\beta},
\end{aligned}
$$

where $\sigma\left(\mathrm{m}^{3} \mathrm{~m}^{-3}\right)$ represents the standard deviation of $\overline{\boldsymbol{\theta}}_{t}^{\text {rep }}$, and $R(-)$ is the regularization parameter.

The core issue of the ATI approach is to obtain the $\overline{\boldsymbol{\theta}}_{t}^{\text {rep }}$ and minimize the cost function of Eq. (B8) to obtain $\beta$ and $R$. The $\overline{\boldsymbol{\theta}}_{t}^{\text {rep }}$ can be retrieved from the apparent thermal inertia $\tau$ via empirical regression $g(\tau)$, and $\tau$ has a strong connection with the surface status, e.g. land surface temperature and albedo, which is defined as

$\tau=C \frac{1-a}{A}$,

where $C(-)$ represents the solar correction factor, $a(-)$ represents the surface albedo, and $A(\mathrm{~K})$ represents the amplitude of the diurnal temperature cycle. The albedo and land surface temperature data obtained from the MODIS MCD43A3 and MYD11A1/MOD11A1 version 6 products are used to derive the ATI according to Eq. (B9) in this study.

The solar correlation factor $C$ in Eq. (B9) is computed as

$$
\begin{aligned}
C= & \sin \varphi \sin \delta\left(1-\tan ^{2} \varphi \tan ^{2} \delta\right)^{1 / 2} \\
& +\cos \varphi \cos \delta \arccos (-\tan \varphi \tan \delta),
\end{aligned}
$$

with

$$
\begin{aligned}
\delta= & 0.00691-0.399912 \cos (\gamma)+0.070257 \sin (\gamma) \\
& -0.006758 \cos (2 \gamma)+0.000907 \sin (2 \gamma) \\
& -0.002697 \cos (3 \gamma)+0.00148 \sin (3 \gamma)
\end{aligned}
$$

and

$\gamma=\frac{2 \pi\left(n_{\mathrm{d}}-1\right)}{365.25}$, 
where $\varphi$ represents the latitude ( $\mathrm{rad}), \delta$ represents the solar declination (rad), and $n_{\mathrm{d}}$ represents the Julian day number.

The amplitude of the diurnal land surface temperature (LST) $A$ is estimated as $\mathrm{LST}_{\max }-\mathrm{LST}_{\text {min }}$ for a single day. Finally, we use the regression analysis between in situ SM measurements $(\boldsymbol{\theta})$ at each monitoring site and corresponding ATI $(\tau)$ to obtain the $g(\cdot)$ form.

There are 17 and 12 monitoring sites participating in the regression analysis for the Maqu and Shiquanhe networks during the periods of November 2009-October 2010 and August 2018-July 2019, respectively. The ATI cannot be obtained for each monitoring site on every day since the satellite-based LST data are contaminated by clouds. In order to make full use of the data, we make the ATI-SM pair for the first monitoring site on the first day no. 1, the pair for the 17th (12th) monitoring site in the Maqu (Shiquanhe) network on the first day no. 17 (no. 12), the pair for the first monitoring site on the second day no. 18 (no. 13), and so on. Later on, we select a certain number of ATI-SM pairs (e.g. 40, 50, 60, 70, 80,90 , and 100) as a group to compute the averaged ATI and $\mathrm{SM}$ and construct the most reliable (i.e. with the maximum $R^{2}$ ) regression relationship between them. If the ATI or SM data on one day are missing, this pair is ignored. As shown in Fig. B1, the empirical relationship is generated from 80 pairs of ATI and SM averaged for the Maqu and Shiquanhe networks.

When the empirical relationship $g(\cdot)$ is determined, the regional-average SM can be derived from grid-averaged ATI by the function $g(\cdot)$, which is regarded as $\overline{\boldsymbol{\theta}}_{t}^{\text {rep }}$ in Eq. (B8). Finally, the optimal $\boldsymbol{\beta}(\hat{\boldsymbol{\beta}})$ is obtained by minimizing the cost function (i.e. Eq. B8), and the upscaled SM can be estimated as

$\overline{\boldsymbol{\theta}}_{t}^{\mathrm{ups}}=\hat{\boldsymbol{\beta}} \boldsymbol{\theta}_{t}^{\mathrm{obs}}$.

Detailed description of the ATI method can be found in Qin et al. (2013). 
(a) Maqu

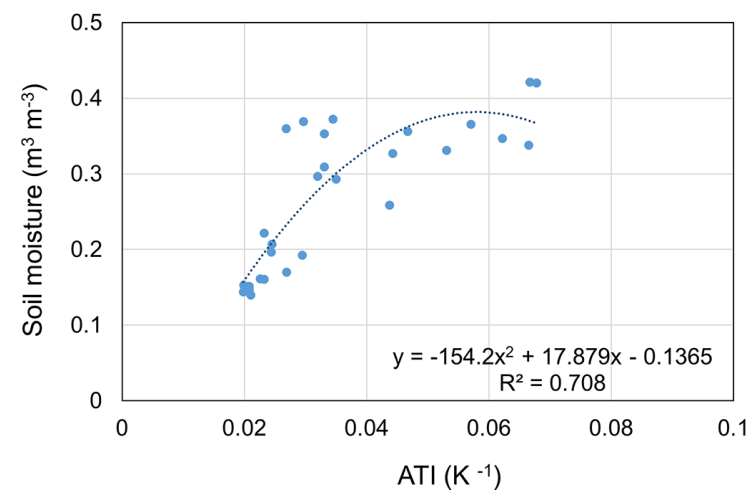

(b) Shiquanhe

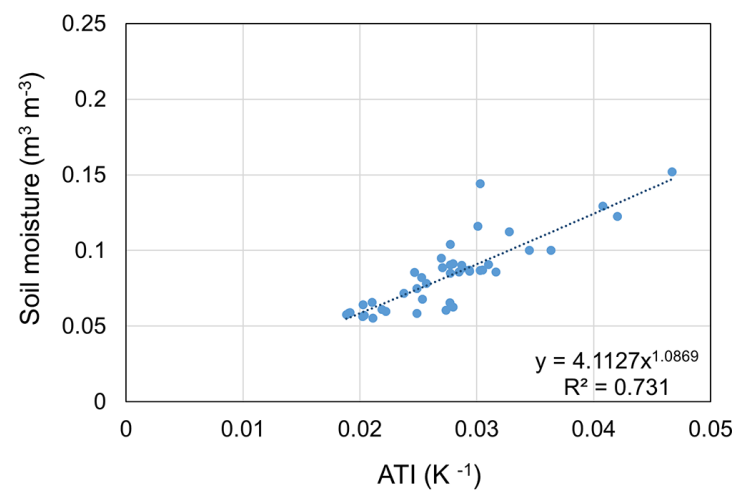

Figure B1. Empirical relationship between 80 pairs of ATI and SM averaged for the (a) Maqu and (b) Shiquanhe networks.
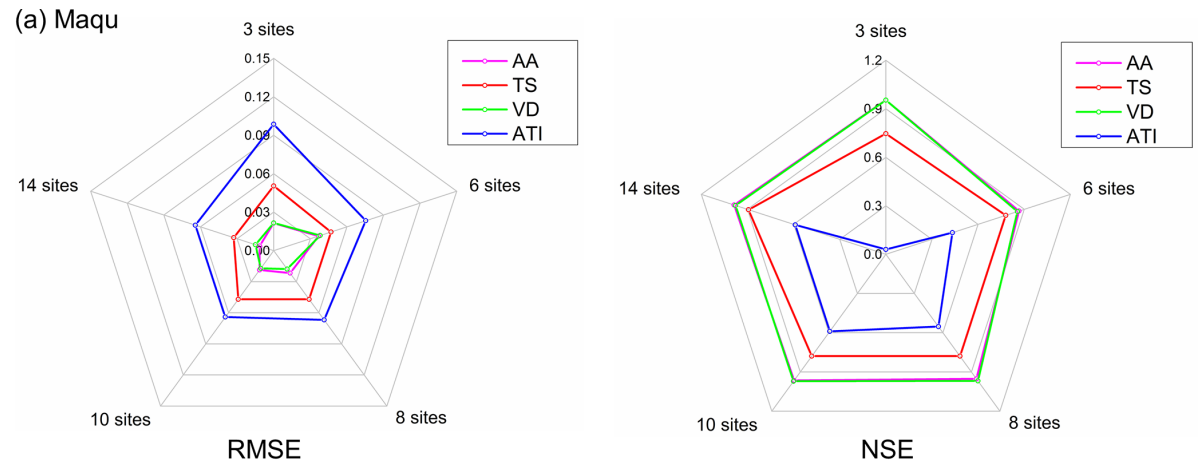

(b) Shiquanhe
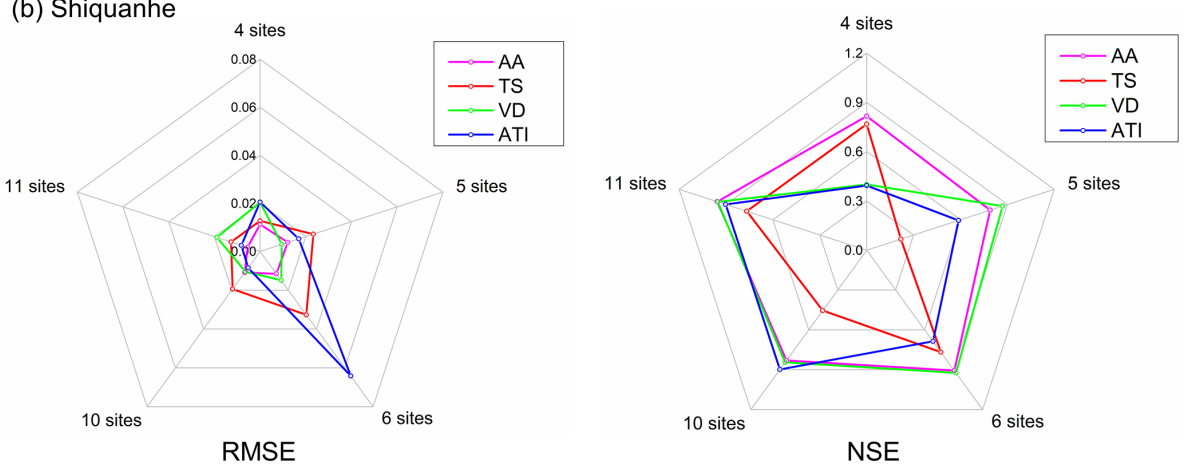

Figure B2. Radar diagram of error statistics (i.e. RMSE and NSE) computed between the $\mathrm{SM}_{\text {truth }}$ produced by the AA-max and the upscaled SM produced by the four upscaling methods with input of a different number of available monitoring sites for the (a) Maqu and (b) Shiquanhe networks.

Table B1. Evaluation metrics computed for the upscaled SM produced with four methods with input of the maximum available monitoring sites. The bold font represents the best performance with the lowest CEC value.

\begin{tabular}{lrrr|rrr}
\hline Methods & \multicolumn{3}{c|}{ Maqu } & \multicolumn{3}{c}{ Shiquanhe } \\
\cline { 2 - 7 } & MRD & $\sigma(\mathrm{RD})$ & CEC & MRD & $\sigma(\mathrm{RD})$ & CEC \\
\hline AA-max & 0.009 & 0.054 & $\mathbf{0 . 0 5 5}$ & 0.012 & 0.046 & $\mathbf{0 . 0 4 7}$ \\
TS-max & 0.022 & 0.089 & 0.092 & 0.011 & 0.114 & 0.114 \\
VD-max & -0.026 & 0.064 & 0.069 & -0.042 & 0.033 & 0.053 \\
ATI-max & -0.005 & 0.145 & 0.145 & 0.016 & 0.068 & 0.070 \\
\hline
\end{tabular}


Table B2. Error statistics computed between the SM obtained by the four upscaling methods with input of the minimum available monitoring sites and the $\mathrm{SM}_{\text {truth }}$ produced by the AA-max for the Maqu and Shiquanhe networks.

\begin{tabular}{lrrrr}
\hline & bias $\left(\mathrm{m}^{3} \mathrm{~m}^{-3}\right)$ & $\mathrm{RMSE}\left(\mathrm{m}^{3} \mathrm{~m}^{-3}\right)$ & $\mathrm{ubRMSE}\left(\mathrm{m}^{3} \mathrm{~m}^{-3}\right)$ & $\mathrm{NSE}$ \\
\hline Maqu & & & & \\
\hline AA-min & 0.005 & 0.022 & 0.021 & 0.954 \\
TS-min & 0.025 & 0.050 & 0.044 & 0.747 \\
VD-min & -0.007 & 0.022 & 0.020 & 0.954 \\
ATI-min & -0.052 & 0.099 & 0.084 & 0.030 \\
\hline Shiquanhe & & & & \\
\hline AA-min & 0.010 & 0.011 & 0.005 & 0.816 \\
TS-min & -0.001 & 0.013 & 0.013 & 0.768 \\
VD-min & 0.019 & 0.020 & 0.006 & 0.400 \\
ATI-min & -0.001 & 0.021 & 0.021 & 0.393 \\
\hline
\end{tabular}


Author contributions. PZ, DZ, RvdV, and ZS designed the framework of this work. PZ performed the computations and data analysis and wrote the manuscript. DZ, RvdV, and ZS supervised the progress of this work and provided critical suggestions, and they revised the manuscript. ZS and JW designed the setup of Tibet-Obs. $\mathrm{YZ}, \mathrm{XW}$, and ZW were involved in maintaining the Tibet-Obs and downloading the original measurements. PZ, ZW, and JC organized the data.

Competing interests. The authors declare that they have no conflict of interest.

Acknowledgements. This study was supported by the Strategic Priority Research Program of the Chinese Academy of Sciences (grant no. XDA20100103) and the National Natural Science Foundation of China (grant nos. 41971308 and 41871273).

Financial support. This research has been supported by the Strategic Priority Research Program of the Chinese Academy of Sciences (grant no. XDA20100103) and the National Natural Science Foundation of China (grant nos. 41971308 and 41871273).

Review statement. This paper was edited by Sibylle K. Hassler and reviewed by Mirko Mälicke and one anonymous referee.

\section{References}

Albergel, C., Dutra, E., Munier, S., Calvet, J.-C., Munoz-Sabater, J., de Rosnay, P., and Balsamo, G.: ERA-5 and ERA-Interim driven ISBA land surface model simulations: which one performs better?, Hydrol. Earth Syst. Sci., 22, 3515-3532, https://doi.org/10.5194/hess-22-3515-2018, 2018.

Benninga, H.-J. F., Carranza, C. D. U., Pezij, M., van Santen, P., van der Ploeg, M. J., Augustijn, D. C. M., and van der Velde, R.: The Raam regional soil moisture monitoring network in the Netherlands, Earth Syst. Sci. Data, 10, 61-79, https://doi.org/10.5194/essd-10-61-2018, 2018.

Bi, H. and Ma, J.: Evaluation of simulated soil moisture in GLDAS using in-situ measurements over the Tibetan Plateau, International Geoscience and Remote Sensing Symposium (IGARSS), Milan, Italy, July 2015, 4825-4828, https://doi.org/10.1109/IGARSS.2015.7326910, 2015.

Chen, Y., Yang, K., Qin, J., Zhao, L., Tang, W., and Han, M.: Evaluation of AMSR-E retrievals and GLDAS simulations against observations of a soil moisture network on the central Tibetan Plateau, J. Geophys. Res.-Atmos., 118, 4466-4475, https://doi.org/10.1002/jgrd.50301, 2013.

Cheng, M., Zhong, L., Ma, Y., Zou, M., Ge, N., Wang, X., and Hu, Y.: A study on the assessment of multi-source satellite soil moisture products and reanalysis data for the Tibetan Plateau, Remote Sens., 11, 1196, https://doi.org/10.3390/rs11101196, 2019.

Colliander, A., Jackson, T. J., Bindlish, R., Chan, S., Das, N., Kim, S. B., Cosh, M. H., Dunbar, R. S., Dang, L., Pashaian, L., Asanuma, J., Aida, K., Berg, A., Rowlandson, T.,
Bosch, D., Caldwell, T., Caylor, K., Goodrich, D., al Jassar, H., Lopez-Baeza, E., Martínez-Fernández, J., González-Zamora, A., Livingston, S., McNairn, H., Pacheco, A., Moghaddam, M., Montzka, C., Notarnicola, C., Niedrist, G., Pellarin, T., Prueger, J., Pulliainen, J., Rautiainen, K., Ramos, J., Seyfried, M., Starks, P., Su, Z., Zeng, Y., van der Velde, R., Thibeault, M., Dorigo, W., Vreugdenhil, M., Walker, J. P., Wu, X., Monerris, A., O’Neill, P. E., Entekhabi, D., Njoku, E. G., and Yueh, S.: Validation of SMAP surface soil moisture products with core validation sites, Remote Sens. Environ., 191, 215-231, https://doi.org/10.1016/j.rse.2017.01.021, 2017.

Dente, L., Su, Z., and Wen, J.: Validation of SMOS soil moisture products over the Maqu and Twente Regions, Sensors (Switzerland), 12, 9965-9986, https://doi.org/10.3390/s120809965, $2012 \mathrm{a}$.

Dente, L., Vekerdy, Z., Wen, J., and Su, Z.: Maqu network for validation of satellite-derived soil moisture products, Int. J. Appl. Earth Obs., 17, 55-65, https://doi.org/10.1016/j.jag.2011.11.004, 2012 b.

Famiglietti, J. S., Ryu, D., Berg, A. A., Rodell, M., and Jackson, T. J.: Field observations of soil moisture variability across scales, Water Resour. Res., 44, 1-16, https://doi.org/10.1029/2006WR005804, 2008.

Gao, S., Zhu, Z., Weng, H., and Zhang, J.: Upscaling of sparse in situ soil moisture observations by integrating auxiliary information from remote sensing, Int. J. Remote Sens., 38, 4782-4803, https://doi.org/10.1080/01431161.2017.1320444, 2017.

Gilbert, R. O.: Statistical Methods for Environmental Pollution Monitoring, United States, https://www.osti.gov/biblio/7037501 (last access: 23 June 2021), 1987.

GMAO, Global Modeling and Assimilation Office: MERRA-2 tavg1_2d_lnd_Nx: 2d, 1-Hourly, Time-Averaged, Single-Level, Assimilation, Land Surface Diagnostics V5.12.4, Goddard Earth Sciences Data and Information Services Center (GES DISC), Greenbelt, MD, USA, 2015.

Jacobs, J. M., Mohanty, B. P., Hsu, E.-C., and Miller, D.: SMEX02: Field scale variability, time stability and similarity of soil moisture, Remote Sens. Environ., 92, 436-446, https://doi.org/10.1016/j.rse.2004.02.017, 2004.

Ju, F., An, R., and Sun, Y.: Immune evolution particle filter for soil moisture data assimilation, Water (Switzerland), 11, 211, https://doi.org/10.3390/w11020211, 2019.

Kang, J., Jin, R., Li, X., and Zhang, Y.: Block Kriging With Measurement Errors: A Case Study of the Spatial Prediction of Soil Moisture in the Middle Reaches of Heihe River Basin, IEEE Geosci. Remote S., 14, 87-91, https://doi.org/10.1109/LGRS.2016.2628767, 2017.

Li, C., Lu, H., Yang, K., Han, M., Wright, J. S., Chen, Y., Yu, L., Xu, S., Huang, X., and Gong, W.: The evaluation of SMAP enhanced soil moisture products using high-resolution model simulations and in-situ observations on the Tibetan Plateau, Remote Sens., 10, 1-16, https://doi.org/10.3390/rs10040535, 2018.

Liu, J., Chai, L., Lu, Z., Liu, S., Qu, Y., Geng, D., Song, Y., Guan, Y., Guo, Z., Wang, J., and Zhu, Z.: Evaluation of SMAP, SMOSIC, FY3B, JAXA, and LPRM Soil moisture products over the Qinghai-Tibet Plateau and Its surrounding areas, Remote Sens., 11, 211, https://doi.org/10.3390/rs11070792, 2019.

Mann, H. B.: Nonparametric Tests Against Trend, Econometrica, 13, 245-259, https://doi.org/10.2307/1907187, 1945. 
Moghaddam, M., Clewley, D., Silva, A., and Akbar, R.: The SoilSCAPE Network Multiscale In-situ Soil Moisture Measurements: Innovations in Network Design and Approaches to Upscaling in Support of SMAP, in AGU Fall Meeting Abstracts, vol. 2014, IN11A-3599, online availbale from: https: //ui.adsabs.harvard.edu/abs/2014AGUFMIN11A3599M (last access: 23 June 2021), 2014.

Muñoz-Sabater, J., Dutra, E., Balsamo, G., Schepers, D., Albergel, C., Boussetta, S., Agusti-Panareda, A., Zsoter, E., and Hersbach, H.: ERA5-Land: an improved version of the ERA5 reanalysis land component, Joint ISWG and LSA-SAF Workshop IPMA, Lisbon, July 2018, 26-28, 2018.

Qin, J., Yang, K., Lu, N., Chen, Y., Zhao, L., and Han, M.: Spatial upscaling of in-situ soil moisture measurements based on MODIS-derived apparent thermal inertia, Remote Sens. Environ., 138, 1-9, https://doi.org/10.1016/j.rse.2013.07.003, 2013.

Qin, J., Zhao, L., Chen, Y., Yang, K., Yang, Y., Chen, Z., and Lu, H.: Inter-comparison of spatial upscaling methods for evaluation of satellite-based soil moisture, J. Hydrol., 523, 170-178, https://doi.org/10.1016/j.jhydrol.2015.01.061, 2015.

Rodell, M., Houser, P. R., Jambor, U., Gottschalck, J., Mitchell, K., Meng, C.-J., Arsenault, K., Cosgrove, B., Radakovich, J., Bosilovich, M., Entin, J. K., Walker, J. P., Lohmann, D., and Toll, D.: The Global Land Data Assimilation System, B. Am. Meteorol. Soc., 85, 381-394, https://doi.org/10.1175/BAMS-85-3-381, 2004.

Sen, P. K.: Estimates of the Regression Coefficient Based on Kendall's Tau, J. Am. Stat. Assoc., 63, 1379-1389, https://doi.org/10.1080/01621459.1968.10480934, 1968.

Su, Z., Wen, J., Dente, L., van der Velde, R., Wang, L., Ma, Y., Yang, K., and Hu, Z.: The Tibetan Plateau observatory of plateau scale soil moisture and soil temperature (TibetObs) for quantifying uncertainties in coarse resolution satellite and model products, Hydrol. Earth Syst. Sci., 15, 2303-2316, https://doi.org/10.5194/hess-15-2303-2011, 2011.

Su, Z., De Rosnay, P., Wen, J., Wang, L., and Zeng, Y.: Evaluation of ECMWF's soil moisture analyses using observations on the Tibetan Plateau, J. Geophys. Res.-Atmos., 118, 5304-5318, https://doi.org/10.1002/jgrd.50468, 2013.

Tarantola, A.: Inverse Problem Theory and Methods for Model Parameter Estimation, Society for Industrial and Applied Mathematics, University City Science Center Philadelphia, USA, 2005.

Topp, G. C., Davis, J. L., and Annan, A. P.: Electromagnetic determination of soil water content: Measurements in coaxial transmission lines, Water Resour. Res., 16, 574-582, https://doi.org/10.1029/WR016i003p00574, 1980.

Vachaud, G., Passerat De Silans, A., Balabanis, P., and Vauclin, M.: Temporal Stability of Spatially Measured Soil Water Probability Density Function1, Soil Sci. Soc. Am. J., 49, 822-828, https://doi.org/10.2136/sssaj1985.03615995004900040006x, 1985.

Velde, R.: Soil moisture remote sensing using active microwaves and land surface modelling, ITC Printing Department, Enschede, the Netherlands, 2010.

van der Velde, R., Salama, M. S., Pellarin, T., Ofwono, M., Ma, Y., and $\mathrm{Su}, \mathrm{Z}$.: Long term soil moisture mapping over the Tibetan plateau using Special Sensor Microwave/Imager, Hydrol. Earth Syst. Sci., 18, 1323-1337, https://doi.org/10.5194/hess-18-13232014, 2014a. van der Velde, R., Su, Z., and Wen, J.: Roughness determination from multi-angular ASAR Wide Swath mode observations for soil moisture retrieval over the Tibetan Plateau, Proceedings of the European Conference on Synthetic Aperture Radar, EUSAR, Proceeding (August 2011), VDE Verlag, Berlin, Germany, 163 165, 2014b.

van der Velde, R., Colliander, A., Pezij, M., Benninga, H.-J. F., Bindlish, R., Chan, S. K., Jackson, T. J., Hendriks, D. M. D., Augustijn, D. C. M., and Su, Z.: Validation of SMAP L2 passiveonly soil moisture products using upscaled in situ measurements collected in Twente, the Netherlands, Hydrol. Earth Syst. Sci. 25, 473-495, https://doi.org/10.5194/hess-25-473-2021, 2021.

Van doninck, J., Peters, J., De Baets, B., De Clercq, E. M., Ducheyne, E., and Verhoest, N. E. C.: The potential of multitemporal Aqua and Terra MODIS apparent thermal inertia as a soil moisture indicator, Int. J. Appl. Earth Obs., 13, 934-941, https://doi.org/10.1016/j.jag.2011.07.003, 2011.

Veroustraete, F., Li, Q., Verstraeten, W. W., Chen, X., Bao, A., Dong, Q., Liu, T., and Willems, P.: Soil moisture content retrieval based on apparent thermal inertia for Xinjiang province in China, Int. J. Remote Sens., 33, 3870-3885, https://doi.org/10.1080/01431161.2011.636080, 2012.

Wang, J., Ge, Y., Song, Y., and Li, X.: A Geostatistical Approach to Upscale Soil Moisture With Unequal Precision Observations, IEEE Geosci. Remote S., 11, 2125-2129, https://doi.org/10.1109/LGRS.2014.2321429, 2014.

Wei, Z., Meng, Y., Zhang, W., Peng, J., and Meng, L.: Downscaling SMAP soil moisture estimation with gradient boosting decision tree regression over the Tibetan Plateau, Remote Sens. Environ., 225, 30-44, https://doi.org/10.1016/j.rse.2019.02.022, 2019.

Yang, K., Chen, Y., He, J., Zhao, L., Lu, H., and Qin, J.: Development of a daily soil moisture product for the period of 2002-2011 in Mainland China, Science China Earth Sciences, 63, 11131125, https://doi.org/10.1007/s11430-019-9588-5, 2020.

Zeng, J., Li, Z., Chen, Q., Bi, H., Qiu, J., and Zou, P.: Evaluation of remotely sensed and reanalysis soil moisture products over the Tibetan Plateau using in-situ observations, Remote Sens. Environ., 163, 91-110, https://doi.org/10.1016/j.rse.2015.03.008, 2015.

Zeng, Y., Su, Z., Van Der Velde, R., Wang, L., Xu, K., Wang, X., and Wen, J.: Blending satellite observed, model simulated, and in situ measured soil moisture over Tibetan Plateau, Remote Sens., 8, 1-22, https://doi.org/10.3390/rs8030268, 2016.

Zhang, P., Zheng, D., van der Velde, R., Wen, J., Zeng, Y., Wang, X., Wang, Z., Chen, J., and Su, Z.: A 10 year (2009-2019) surface soil moisture dataset produced based on in situ measurements collected from the Tibet-Obs, 4TU.ResearchData, Dataset, https://doi.org/10.4121/12763700.v7, 2020.

Zhang, Q., Fan, K., Singh, V. P., Sun, P., and Shi, P.: Evaluation of Remotely Sensed and Reanalysis Soil Moisture Against In Situ Observations on the HimalayanTibetan Plateau, J. Geophys. Res.-Atmos., 123, 7132-7148, https://doi.org/10.1029/2017JD027763, 2018.

Zhao, H., Zeng, Y., Lv, S., and Su, Z.: Analysis of soil hydraulic and thermal properties for land surface modeling over the Tibetan Plateau, Earth Syst. Sci. Data, 10, 1031-1061, https://doi.org/10.5194/essd-10-1031-2018, 2018.

Zhao, L., Yang, K., Qin, J., Chen, Y., Tang, W., Montzka, C., Wu, H., Lin, C., Han, M., and Vereecken, H.: Spa- 
tiotemporal analysis of soil moisture observations within a Tibetan mesoscale area and its implication to regional soil moisture measurements, J. Hydrol., 482, 92-104, https://doi.org/10.1016/j.jhydrol.2012.12.033, 2013.

Zhao, W., Li, A., Jin, H., Zhang, Z., Bian, J., and Yin, G.: Performance evaluation of the triangle-based empirical soil moisture relationship models based on Landsat-5 TM data and in situ measurements, IEEE T. Geosci. Remote, 55, 2632-2645, https://doi.org/10.1109/TGRS.2017.2649522, 2017.

Zheng, D., van der Velde, R., Su, Z., Wang, X., Wen, J., Booij, M. J., Hoekstra, A. Y., and Chen, Y.: Augmentations to the Noah Model Physics for Application to the Yellow River Source Area. Part I: Soil Water Flow, J. Hydrometeorol., 16, 2659-2676, https://doi.org/10.1175/JHM-D-14-0198.1, 2015a.

Zheng, D., van der Velde, R., Su, Z., Wang, X., Wen, J., Booij, M. J., Hoekstra, A. Y., and Chen, Y.: Augmentations to the Noah Model Physics for Application to the Yellow River Source Area. Part II: Turbulent Heat Fluxes and Soil Heat Transport, J. Hydrometeorol., 16, 2677-2694, https://doi.org/10.1175/JHM-D-14-0199.1, 2015 b.
Zheng, D., van der Velde, R., Wen, J., Wang, X., Ferrazzoli, P., Schwank, M., Colliander, A., Bindlish, R., and $\mathrm{Su}, \mathrm{Z}$.: Assessment of the SMAP Soil Emission Model and Soil Moisture Retrieval Algorithms for a Tibetan Desert Ecosystem, IEEE T. Geosci. Remote, 56, 3786-3799, https://doi.org/10.1109/TGRS.2018.2811318, 2018a.

Zheng, D., Wang, X., van der Velde, R., Ferrazzoli, P., Wen, J., Wang, Z., Schwank, M., Colliander, A., Bindlish, R., and Su, Z.: Impact of surface roughness, vegetation opacity and soil permittivity on L-band microwave emission and soil moisture retrieval in the third pole environment, Remote Sens. Environ., 209, 633647, https://doi.org/10.1016/j.rse.2018.03.011, 2018b.

Zheng, D., Wang, X., van der Velde, R., Schwank, M., Ferrazzoli, P., Wen, J., Wang, Z., Colliander, A., Bindlish, R., and Su, Z.: Assessment of Soil Moisture SMAP Retrievals and ELBARA-III Measurements in a Tibetan Meadow Ecosystem, IEEE Geosci. Remote S., 16, 1407-1411, https://doi.org/10.1109/lgrs.2019.2897786, 2019. 